\title{
MODIFYING WHEAT BRAN TO IMPROVE ITS HEALTH BENEFITS
}

Lise Deroover ${ }^{\mathrm{a}}$, Yaxin Tie ${ }^{\mathrm{a}}$, Joran Verspreet ${ }^{\mathrm{b}}$, Christophe M. Courtin ${ }^{\mathrm{b}, \mathrm{c}}$ and Kristin Verbeke $\mathrm{C}^{\mathrm{a}, \mathrm{c}, *}$

${ }^{a}$ Translational Research in Gastrointestinal Disorders, KU Leuven, Leuven 3000, Belgium; lise.deroover@kuleuven.be; yaxin.tie@kuleuven.be

bLaboratory of Food Chemistry and Biochemistry, KU Leuven, Leuven 3001, Belgium;

joran.verspreet@hotmail.com, christophe.courtin@kuleuven.be

${ }^{c}$ Leuven Food Science and Nutrition Research Centre, KU Leuven, Leuven, 3000 Belgium

\section{*Corresponding author:}

Kristin Verbeke

Translational Research in Gastrointestinal Disorders, KU Leuven

Herestraat 49 Box 701

3000 Leuven, Belgium

Tel.: +3216330150; Fax: +3216330723

E-mail address: kristin.verbeke@kuleuven.be 
Keywords: wheat bran modifications, faecal bulking, gut microbiota, short-chain fatty acids, antioxidant capacities

\begin{abstract}
Consumption of wheat bran (WB) has been associated with improved gastrointestinal health and a reduced risk for colorectal cancer, cardiovascular diseases and metabolic disorders. These benefits are likely mediated by a combination of mechanisms, including colonic fermentation of the WB fibre, faecal bulking and the prevention of oxidative damage due to its antioxidant capacities. The relative importance of those mechanisms is not known and may differ for each health effect. WB has been modified by reducing particle size, heat treatment or modifying tissue composition to improve its technological properties and facilitate bread making processes. However, the impact of those modifications on human health has not been fully elucidated. Some modifications reinforce whereas others attenuate the health effects of coarse WB. This review summarises available WB modifications, the mechanisms by which WB induces health benefits, the impact of WB modifications thereon and the available evidence for these effects from in vitro and in vivo studies.
\end{abstract}

\title{
INTRODUCTION
}

In Europe, the flour milling industry produces about 35 million tons of flour per year from about 45 million tons of wheat and rye (European Flour Millers 2016). This process also results in the production of an estimated 6.5 million tons of bran which is mostly used in animal feed as a source of phosphorus, to lighten dense, heavy feed mixtures and to increase fibre intake in animals (European Flour Millers 2016).

Because wheat bran (WB) is an excellent source of fibre that is readily available at a low price, it is increasingly used

in human diets under the form of cereal-based and bakery products (European Flour Millers 2016). WB consumption has also been associated with health benefits such as 
gastrointestinal health and a decreased risk for the development of cardiovascular diseases (CVD), cancer and metabolic diseases (Stevenson et al. 2012). Modifications of the tissue composition and physical properties of bran can improve its technological properties but may also affect specific health effects. Reducing WB particle size improves the accessibility of nutrients within the bran (Rosa et al. 2013), such as phenolic antioxidants, whereas heat treatment inactivates several enzymes, thereby reducing its biochemical reactivity (Mosharraf, Kadivar, and Shahedi 2009).

Despite the benefits associated with WB consumption, the use of WB also raises some concerns. Cereals can be contaminated with mycotoxins produced by a variety of fungi that colonise the crops during growing or storage. Depending on their concentrations, mycotoxins can induce adverse health effects in humans and animals. However, applying appropriate pre- and postharvest strategies can mitigate the risk for mycotoxin contamination (Cheli et al. 2017). Furthermore, WB also contains some anti-nutrients like phytates that form strong complexes with minerals and in this way, may hamper the absorption and reduce the bioavailability of the minerals.

This review provides an overview of available modifications of $\mathrm{WB}$, the putative mechanisms by which modified WB affects health and the available evidence on those health benefits from in vitro, animal and human studies.

\section{WHEAT BRAN: DEFINITION, STRUCTURE AND COMPOSITION}

WB refers to the outer layers of the wheat kernel, which surround the germ and the endosperm. It is composed of different histological tissue layers (Figure 1a, b). Starting from the outside of the wheat kernel, one observes the pericarp (epidermis, hypodermis, cross cells and tubular cells), the seed coat or testa, the nucellar epidermis and the aleurone layer, which is tightly bound to the seed coat (Delcour and Hoseney 2010). In the jargon of

millers, the term bran is a collective name for all the above tissue layers together with some 
residual starchy endosperm that remains attached to the aleurone layer after milling. From the botanical point of view, the aleurone layer and the residual starchy endosperm are not part of the bran.

The pericarp is the outermost layer of the bran fraction and is made of three layers: epicarp, mesocarp and endocarp. It is composed of empty cells, mostly consisting of cell wall polysaccharides, such as branched heteroxylans and cellulose, with numerous cross-links between the polymer chains, formed by ferulic acid dimers (Brouns et al. 2012, Fincher and Stone 1986). The arabinoxylan in the pericarp layer has a highly branched structure (high arabinose to xylose ratio) and is therefore to large extent resistant to bacterial fermentation (Barron, Surget, and Rouau 2007).

The aleurone layer, in contrast, is a monocellular layer located at the inner site of the bran that contains $\beta$-glucans, few proteins and high amounts of lowly substituted arabinoxylan and esterified ferulic acid monomers (Brouns et al. 2012). Due to the low arabinose to xylose ratio, the arabinoxylans in aleurone are easily degraded by the gut microbiota. Moreover, the aleurone layer is particularly rich in nutrients like the minerals iron, magnesium, zinc and calcium and almost all of the B-group vitamins.

Coarse WB has a particle size between 1500 and $2000 \mu \mathrm{m}$ with a wide particle size distribution. It is usually composed of $43-62 \%$ dietary fibre which mainly consists of arabinoxylan (AX) and to a lesser extent of beta-glucan, cellulose, fructan and lignin. Furthermore, WB consist of 6-19\% starch, $14-18 \%$ protein, $5-8 \%$ ash and $3-6 \%$ lipids on dry matter basis (Figure 1c) (Shenoy and Prakash 2002, Hemery et al. 2009, Zhang and Moore 1997). 


\section{MODIFICATION OF WHEAT BRAN}

\section{Wheat Bran with Reduced Particle Size (WB RPS)}

Usually, the particle size of coarse WB is reduced by milling after which the WB samples are sieved (Brewer et al. 2014, Jacobs et al. 2015, Majzoobi et al. 2014). Different types of milling are possible (Henrion et al. 2018). During jet milling, WB is subjected to a high speed jet of compressed air or another inert gas. The reduction in particle size is merely the result of the high-velocity collisions between WB particles themselves, with no grinding material involved. Ball milling, in contrast, exposes WB particles to high energy collisions of balls, during which particle size is reduced through impact and high friction. During both types of milling, the milling chamber can be cooled with liquid nitrogen, which is referred to as cryogenic grinding or milling. Cryo-milling prevents the mill and material from overheating, but also and more importantly, keeps the material in a glassy, embrittled state, which facilitates the particle size reduction and preserves important components within the milled material.

Besides milling, other techniques, such as microfluidisation and extrusion have also often been used to reduce WB particle size. During microfluidisation a suspension of WB and water is pushed at a high pressure through different consecutive interaction chambers with diameters varying in size (Wang et al. 2012). In contrast, during extrusion, high temperature and high pressure is built up into a stationary barrel containing a tightly fitting rotating screw that pushes the bran particles towards a die at the end of the barrel (Andersson et al. 2017). Although particle size reduction and increasing the specific surface area of the bran is the main purpose of these treatments, both also increase the water holding capacity, swelling capacity and bulking capacity of the WB as it usually 'puffs' or expands and changes texture when pressure and forces are applied (Wang et al. 2012). 
The tissue composition of WB RPS does not differ from coarse WB, although the accessibility of the cell material and hence the fermentability may be different (Jenkins, Kendall, Vuksan, Augustin, Mehling, et al. 1999, Stewart and Slavin 2009).

\section{Heat Treated Wheat Bran (HT-WB)}

Treating WB with heat is a well-known method to reduce its biochemical reactivity without changing its chemical composition or particle size. One can distinguish wet heat treatment such as boiling, steam cooking or autoclaving (Majzoobi et al. 2014, Mosharraf, Kadivar, and Shahedi 2009) and dry heat treatment such as toasting. Both treatments inactivate enzymes like endopeptidase, $\alpha$-amylase and endoxylanase in the bran (De Almeida et al. 2014, de Kock, Taylor, and Taylor 1999, Nandeesh, Jyotsna, and Rao 2011, Sudha, Ramasarma, and Venkateswara Rao 2011). In addition, HT-WB has a higher surface hydrophobicity than coarse WB (Jacobs et al. 2016).

\section{Wheat Bran with Modified Tissue Composition}

On lab-scale, aleurone-rich and pericarp-rich bran, can be produced either by manual dissection of whole wheat kernels, which yield the purest bran fractions or by subjecting wheat grains to a debranning process (Brouns et al. 2012). Debranning is a controlled process, during which the outer grain layers, mostly pericarp, are removed either by friction (peeling) or abrasion (pearling) or a combination (Dexter and Wood 1996, Hemery et al. 2007). This process results in polished wheat kernels that yield aleurone-rich bran after milling whereas the pearlings consist of pericarp-enriched bran.

To isolate aleurone and pericarp on a larger scale both wet-fractionation and dry-fractionation processes have been used. Wet-fractionation processes combine enzymatic treatments and wet millings steps, followed by sequential centrifugation and ultra-filtration (Kvist et al. 2010). Pericarp-enriched WB fractions can be obtained after treatment with 
cellulases and endoxylanases. The latter remove the aleurone layer, as they cleave the lowly substituted AX, present in the aleurone and not in the pericarp (Douge et al. 2004).

Dry-fractionation processes, in contrast, only apply physical and mechanical treatments, limiting the biochemical alterations of the aleurone structures (Brouns et al. 2012). They can be used to produce simultaneously aleurone-enriched and pericarp-enriched WB. The procedure comprises a fragmentation step, usually grinding, and a separation step (Hemery et al. 2007). Separation of the particles according to properties like size, mass and density does not yield high purity fractions, due to the low differentiation in size and density of the particles generated after grinding (Brouns et al. 2012). Electrostatic separation of the different wheat bran tissues allows to obtain more pure WB fractions (Hemery et al. 2009).

\section{MECHANISMS BY WHICH (MODIFIED) WHEAT BRAN IMPROVES HEALTH}

\section{Faecal Bulking}

Carbohydrates that are not digested or absorbed in the small intestine, reach the colon where they are (partly) fermented by the gut microbiota. Carbohydrates that are resistant to colonic fermentation have high bulking effects (Monro 2000). Also the water holding capacity of cereal bran is predictive for its faecal bulking effect (Eastwood et al. 1983). Increased bulk leads to increased movement of the colonic content and distends the colon, resulting in a shorter transit time, softer stools and prevention of constipation (Monro 2001, Monro 2002, Topping 2007). In addition, bulk also dilutes the colonic content, leading to lower concentrations of toxins and potentially harmful substances in the stool and a reduced risk for developing colorectal cancer (CRC) (Cummings et al. 1992, Zoran et al. 1997). On average, dietary fibre from WB increases faecal output by $3.7 \pm 0.1 \mathrm{~g} / \mathrm{g}$ fibre/day (de Vries, Miller, and Verbeke 2015), whereas fibre from fruit and vegetables contributes less to faecal bulk ( $0.88 \mathrm{~g} / \mathrm{g}$ fibre/day for fruit and $2.03 \mathrm{~g} / \mathrm{g}$ fibre/day for vegetables) (Cummings et al. 1992, de Vries et al. 2016). 
Processing of WB alters its bulking effects. Pericarp-enriched WB is poorly fermentable and has a high bulking capacity whereas aleurone-rich WB is easily degraded by the gut microbiota and barely contributes to bulking effects (Brouns et al. 2012). Furthermore, WB RPS has a lower water holding capacity compared to coarse bran (Heller et al. 1980, Kirwan et al. 1974), which is related to the loss of micropores and reduced void space between particles due to more efficient stacking of smaller particles (Jacobs et al. 2015) (Figure 2).

\section{Microbiota Composition and Activity}

The human colon is colonised by approximately $10^{14}$ bacteria, which play an important role in the maintenance of host health (Qin et al. 2010). Imbalance in the microbiota composition of the human colon may lead to disorders like obesity and other metabolic diseases (Cani, Everard, and Duparc 2013, Khan et al. 2016). The impact of (modified) WB on the microbiota composition has only scarcely been investigated.

\section{Effects of wheat bran on microbiota composition}

To identify the primary degraders of WB, faecal samples from healthy individuals were inoculated with WB in an in vitro continuous flow system after which WB attached bacteria were identified (Leitch et al. 2007, Duncan et al. 2015). Seventy percent of the bacterial sequences recovered from the WB were from Clostridial cluster XIVa bacteria and consisted mainly of close relatives of the butyrate producers Eubacterium rectale, Roseburia species, E. xylaniphylum and Butyrivibrio species. A recent in vitro study observed increased relative abundances of Bifidobacterium after incubation of faecal slurries with coarse WB, aleuronerich bran, WB RPS and soluble bran (D'hoe et al. 2018). In addition, aleurone-rich bran also increased the proportion of Roseburia and Dorea.

Data from in vivo studies are scarce but consistent. In healthy subjects, clostridia numbers were increased in faeces after consumption of WB-based breakfast cereals ( $48 \mathrm{~g} / \mathrm{day}$ ) for 3 weeks (Costabile et al. 2008). Numbers of Lachnospiraceae, also belonging to the clostridia, 
increased in men with metabolic syndrome after WB supplementation $(27.7 \mathrm{~g} /$ day $)$ for 3 weeks (Salonen et al. 2014), whereas no major alterations in the composition of the faecal microbiota were induced in a similar study in overweight men (Walker et al. 2011). Feeding a high dose of coarse WB (150 g/kg diet) for 6 weeks to piglets increased microbiota richness (expressed as Chao 1 index) in the jejunum, ileum and colon ascendens, although no differences in microbiota composition were observed, when compared to the control diet (Kraler et al. 2016).

\section{Effects of wheat bran on metabolic activity of the microbiota.}

Most studies investigating the fermentation of WB focus on the production of the short-chain fatty acids (SCFA; acetate, propionate and butyrate) as the major metabolites in in vitro fermentation experiments (Adiotomre et al. 1990, Ehle, Robertson, and Van Soest 1982, Karppinen et al. 2000, McBurney and Thompson 1990, Nordlund et al. 2012), as well as in animals (Fleming, Fitch, and Chansler 1989, Mathers and Tagny 1994, McIntyre et al. 1991) and humans (Costabile et al. 2008, Ehle, Robertson, and Van Soest 1982, Lewis and Heaton 1997, Salonen et al. 2014) and compare them with the SCFA levels produced from other cereal brans and other dietary fibre sources. The production of other metabolites has been studied very little so far.

\section{Effects of coarse wheat bran}

Oat bran resulted in highest acetate, butyrate and total SCFA production when fermented in vitro with human faecal microbiota, followed by WB, rice, corn and barley brans (McBurney and Thompson 1990). Accordingly, the in vitro fermentation rate of pre-digested oat bran was higher than that of predigested WB (Nordlund et al. 2012). However, the relative proportion of butyrate was highest after WB fermentation, supporting the observation that WB is primarily colonised by butyrate producing bacteria (Duncan et al. 2015, Leitch et al. 2007). 
Results from in vivo animal studies are consistent with the results from the in vitro batch fermentations. In caecal contents, total SCFA levels, butyrate levels and the proportion of butyrate were higher after consumption of coarse WB compared to other fibre sources (Cheng et al. 1987, Fleming, Fitch, and Chansler 1989, Mathers and Tagny 1994, McIntyre et al. 1991), whereas the proportion of propionate was decreased (Mathers and Tagny 1994) (Table 1). Only one study measured faecal SCFA concentrations in rats and found elevated acetate, propionate and butyrate concentrations during WB administration (McIntyre et al. 1991). Finally, total SCFA and butyrate concentrations were elevated in hepatic portal blood of rats that were fed a WB diet (Cheng et al. 1987).

In most studies, changes in SCFA concentrations were attributed to adaptation of the microbiota to the WB, although the microbiota composition was not measured. An alternative speculation was that some starch in WB escaped digestion in the small intestine and was fermented in the colon (McIntyre et al. 1991).

The effects in human studies were less pronounced compared to the in vitro and animal studies (Table 1). In only one out of three studies, faecal SCFA were significantly higher compared to a fibre-free diet or a cellulose diet (Ehle, Robertson, and Van Soest 1982, Lewis and Heaton 1997, Salonen et al. 2014). However, SCFA measurements in human studies is restricted to faecal samples as it is not possible to sample the caecum or proximal colon in humans. Because of the efficient absorption of SCFA by the colonocytes (up to $95 \%$ of the colonic-produced SCFA are rapidly in the proximal colon), faecal SCFA do not adequately reflect colonic SCFA production (Cummings et al. 1987).

\section{Effects of reducing particle size}

WB RPS raises the expectation that it will yield more SCFA than coarse WB. In addition, milling of the bran particles destroys the cell walls making the fermentable substrates better accessible for bacterial enzymes (Stewart and Slavin 2009). In line with this, SCFA 
concentrations were higher in a recent in vitro fermentation study with fine WB compared to coarse bran although coarse bran yielded the highest proportion of butyrate (Stewart and Slavin 2009).

Data from human intervention studies using WB RPS are limited (Table 1). Whereas faecal butyrate was increased after a 3-week intervention with $20 \mathrm{~g} / \mathrm{d}$ in one study (Jenkins, Kendall, Vuksan, Augustin, Li, et al. 1999), another study did not observe changes in faecal SCFA levels after 9 weeks with 26 g/d (Ehle, Robertson, and Van Soest 1982). The level of particle size reduction does not seem to play a major role in its effects on SCFA production as bran with a particle size of $50 \mu \mathrm{m}$ and of $758 \mu \mathrm{m}$ both increased faecal butyrate levels to the same extent when compared to a control diet (Jenkins, Kendall, Vuksan, Augustin, Li, et al. 1999).

Accordingly, changes in breath hydrogen excretion were observed after a single administration of white bread or bread containing standard or fine whole wheat flour, suggesting that neither particle size of the whole wheat flour, nor fibre content of the breads affected colonic fermentation (Jenkins, Kendall, Vuksan, Augustin, Li, et al. 1999). However, excretion of breath hydrogen is not an appropriate measure for quantitative assessment of colonic fermentation as the fraction of colonic produced hydrogen that is excreted in breath is variable.

\section{Effects of aleurone- and pericarp-rich bran}

Total SCFA were higher when aleurone-rich WB was incubated in vitro with faecal samples compared to pericarp-rich WB (4.9 mmol/g vs $3.5 \mathrm{mmol} / \mathrm{g}$, respectively) (Wood et al. 2002), confirming the better fermentability of aleurone-rich bran. These findings were confirmed in a comparable in vitro experiment by Amrein et al. (Amrein et al. 2003) and in a study with rats and cockerels (Bach Knudsen et al. 1995) and could be anticipated based on the lower substitution of the AX in the aleurone-rich bran fraction. An additional factor that may 
explain the higher fermentability of aleurone-rich WB is its smaller particle size than unmodified WB (Stewart and Slavin 2009). Similarly, butyrate concentrations were higher after fermentation of wheat aleurone compared to $\mathrm{WB}$, and even compared to rye and oat bran, which, however, contain rapidly fermentable fibre (Nordlund et al. 2012).

In rats, caecal acetate and propionate concentrations were higher when aleurone-enriched WB was consumed, while butyrate concentrations were higher in the groups that received coarse WB and pericarp-enriched with bran (Cheng et al. 1987) (Table 1). However, compared to a fibre-free diet, caecal butyrate concentrations were three times higher with aleurone-enriched WB (McIntosh, Royle, and Pointing 2001). In hepatic portal blood, SCFA ratios reflected those in the caecum.

Further modification of aleurone did not improve the production of SCFA from this fraction (Rosa et al. 2013). Although slightly more SCFA were produced in a batch fermentation experiment from ground aleurone $(65 \mu \mathrm{m})$ compared to unmodified aleurone after $8 \mathrm{~h}$ of fermentation, amounts were similar for both aleurone fractions after $24 \mathrm{~h}$. Neither xylanase treatment nor xylanase and feruloyl esterase treatment of the aleurone fraction changed the formation of SCFA (Rosa et al. 2013).

So far, no human intervention trials have been performed with aleurone- and pericarp-rich bran, most likely due to insufficient availability.

\section{Effects of (modified) wheat bran on the fermentation of other carbohydrates}

Rapidly fermentable fibres increase SCFA in the proximal colon whereas slowly fermentable fibres increase more distal SCFA production (McIntyre et al. 1991). As SCFA are rapidly absorbed from the colonic lumen, it is unlikely that proximally produced SCFA reach the distal colon. Because of the important role of SCFA in maintaining health and integrity of the colonic epithelium, increased SCFA concentration along the entire colon has been aimed for by shifting the fermentation of carbohydrates to more distal parts of the colon. WB may 
be a possible candidate to shift fermentation downwards by accelerating the transit of digesta and in this way, physically pushing readily fermentable carbohydrates like resistant starch (RS) and inulin further along the colon.

In rats, faecal starch excretion was increased 4-fold after feeding a diet enriched with raw potato starch compared to a low-starch low-fibre control diet. Addition of $10 \% \mathrm{WB}$ to the potato starch diet further increased starch excretion 10-fold (Young et al. 1996), indicating that RS is less fermented in the presence of WB. To determine the exact site of fermentation of RS and WB and the interaction between both, pigs were fed either a control diet low in RS and WB, a diet supplemented with RS, a diet supplemented with WB and a diet supplemented with RS+WB for 2 weeks (Govers et al. 1999). The pigs were sacrificed to allow sampling of the different parts of the intestine. In the control group and the RS group, starch was readily fermented as negligible amounts of starch were present in the faeces. Adding WB to the control diet or RS diet delayed starch fermentation in the caecum, which, in the RS+WB group, resulted in higher amounts of starch reaching the distal regions of the large bowel and the faeces. Addition of WB to the RS diet increased the amount of starch fermented between the proximal colon and faeces. The site and level of fermentation of WB was not affected by RS. Interestingly, butyrate levels were significantly higher in the pigs that consumed the RS+WB diet compared to the other diets (Govers et al. 1999).

In human subjects with a family history of CRC, faecal starch concentrations and faecal acetate, butyrate and total SCFA levels were higher after consumption of a diet containing RS (22 g/day) and WB (12 g/day) for 3 weeks compared to a control diet or a diet containing only WB (12 g/day) (Muir et al. 2004). Furthermore, the proportion of butyrate was higher whereas the propionate production was lower. As a diet containing only RS was not included, the impact of WB on the RS fermentation could not be assessed. Nevertheless, previous studies with supplementation of RS alone also showed increase faecal SCFA 
concentrations (Cummings et al. 1996, Hylla et al. 1998, Phillips et al. 1995, Scheppach et al. 1988, van Munster, Tangerman, and Nagengast 1994).

In contrast to studies with RS, the site of fermentation of inulin in healthy subjects did not shift when administered together with coarse WB, WB RPS nor pericarp-enriched WB (Deroover et al. 2017). Here, the site of fermentation was estimated by comparing the time of appearance of SCFA in plasma to the oro-caecal transit time.

\section{Antioxidant Properties}

Antioxidants modulate the oxidative status of cells and prevent biologically important molecules such as DNA, proteins and membrane lipids from oxidative damage (Zhou, Su, and $\mathrm{Yu}$ 2004). In this way, they may reduce the risk for chronic diseases such as cardiovascular disease (CVD) and cancer (Liyana-Pathirana and Shahidi 2007, Ross, KamalEldin, and Aman 2004, Yu, Zhou, and W Parry 2005, Zhou, Su, and Yu 2004). Wheat grains contain antioxidant phytochemicals that are mainly located in the aleurone layer (LiyanaPathirana and Shahidi 2007, Mateo Anson et al. 2008, Perez-Jimenez and Saura-Calixto 2005). Antioxidant properties and phytochemical composition of WB strongly differ depending on the origin of the bran (Zhou, Su, and Yu 2004).

Ferulic acid is the most abundant phytochemical in WB. Up to $90 \%$ of the ferulic acid is esterified to AX and other undigestible polysaccharides (Andreasen et al. 2001, Liu 2007, Mateo Anson et al. 2008, Vaher et al. 2010, Yu, Zhou, and W Parry 2005). The unbound fraction is absorbed in the small intestine and conjugated in the liver with glucuronide and sulphate to become bioavailable and exert its beneficial effects (Manach et al. 2004, Zhao, Egashira, and Sanada 2004). In addition, in vitro studies identified esterases that are able to release ferulic acid from dietary fibre in the intestinal mucosa of both rats and humans. Those enzymes may therefore increase the bioavailability of ferulic acid (97). Bound ferulic acid can also be released in the colon, through the action of microbial esterases (Duncan et al. 
2015). This ferulic acid is further metabolised by the microbiota to metabolites such as 3-(3-hydroxyphenyl)-propionic acid and benzoic acid. Both metabolites are absorbed into the systemic circulation and may have antioxidant properties as well (Buchanan, Wallace, and Fry 1996, Kroon et al. 1997). Consequently, both readily available ferulic acid and ferulic acid released by mucosal and microbial esterases contribute to the beneficial antioxidant properties of WB.

Varying methods have been used to evaluate the antioxidant capacity of ferulic acid (Hemery et al. 2010). For example, the 2,2-diphenyl-1-picrylhydrazyl antioxidant assay and the ferrous ion chelating assay are both colorimetric assays, but they work in different ways. The first one measures the capacity of an antioxidant to reduce free radicals, whereas the latter assay measures the capacity of an antioxidant to form complexes with ferrous ions. The use of those different assays hampers comparison amongst studies and extrapolation to general conclusions about antioxidant capacity.

\section{Effects of coarse wheat bran}

In adults, total phenolic concentrations in plasma and urine were significantly higher after ingestion of a test meal containing WB (93 g) compared to ground white rice (Price et al. 2008). Similarly, ferulic acid plasma levels were increased in healthy subjects that consumed whole grain wheat cereals and WB cereals compared to baseline, with higher concentrations upon ingestion of WB (Costabile et al. 2008). These data extend results in rats where plasma ferulic acid concentrations rapidly increased after ingestion of WB and remained constant up to $24 \mathrm{~h}$. Plasma antioxidant activity was also higher in rats that consumed WB compared to rats on a control diet or rats that were fed pure ferulic acid (Rondini et al. 2002, Rondini et al. 2004). 


\section{Effects of reducing particle size}

Reducing the particle size of WB improved its in vitro antioxidant capacity (Zhu et al. 2010). Potential mechanisms include an increased metal chelating activity (Zhu et al. 2010) and improved accessibility of phenolic acids (Brewer et al. 2014, Hemery et al. 2010, Rosa et al. 2013). Whether these mechanisms also result in increased in vivo antioxidant activity still needs to be investigated.

\section{Effects of heat treatment}

The impact of heat treatment on the antioxidant properties of WB has not been studied in vivo. Most studies investigated the effects of baking during bread-making on antioxidant properties (Gélinas and McKinnon 2006, Holtekjølen et al. 2008, Leenhardt et al. 2006, Menga et al. 2010). The availability of phenolic compounds and their antioxidant activity remained relatively stable or slightly increased during baking of bread containing wholemeal wheat flour or WB (Gélinas and McKinnon 2006, Holtekjølen et al. 2008) (Menga et al. 2010). Also hydrothermal processing of wheat kernels increased the accessibility of phenolic acid contents. Unfortunately, whether the antioxidant capacities of the wheat kernels improved was not measured (Zielinski, Kozlowska, and Lewczuk 2001).

\section{Phytate Content}

Phytate is a naturally occurring plant compound that represents the major storage form of phosphorous in cereals and seeds (Cheryan 1980). In wheat, phytate accounts for 1-2\% of the kernel weight and is most abundant in the aleurone and pericarp layer of the bran fraction (Cheryan 1980, Dost and Tokul 2006, Liu et al. 2007, Noort et al. 2010). Phytate binds minerals in cereals and seeds to form phytate-mineral complexes, which decrease the solubility, absorption and digestibility of minerals, resulting in a lower bioavailability of these compounds (Brinch-Pedersen, Sorensen, and Holm 2002, Harland and Oberleas 1987, 
Reddy and Pierson 1994). Although wheat grains have a high phytase activity that hydrolyses the phytates (Brinch-Pedersen, Sorensen, and Holm 2002), absorption of calcium, magnesium, zinc and iron was impaired in most animal and human studies with diets containing high amounts of coarse WB (Cook et al. 1983, Dobbs and Baird 1977, Fly and Czarnecki-Maulden 1996, Sandberg et al. 1982, Simpson, Morris, and Cook 1981, Weaver et al. 1991, Weaver et al. 1996) (Table 2).

Processing of WB, such as particle size reduction, fermentation and heat treatment reduces phytate content in WB with 8 to $90 \%$ (Majzoobi et al. 2014, Watzke 1998) (Table 2). However, whether these modifications also improve mineral availability has neither been investigated in vitro nor in vivo.

The mechanisms by which processing of WB lowers the phytate content in bran have been repeatedly discussed in literature. The acidic conditions $(\mathrm{pH} 4.5)$ during hydrothermal treatment have been related to lower phytate levels (Majzoobi et al. 2014, Mosharraf, Kadivar, and Shahedi 2009). A low pH enhances the endogenous phytase activity of WB resulting in more degradation of the phytic acid. In addition, the washing steps applied in wet heat treatment methods, may remove phytate (Majzoobi et al. 2014, Zielinski, Kozlowska, and Lewczuk 2001). Reducing the particle size of WB increases the accessibility of phytate for phytases, resulting in more phytate hydrolysis. Lastly, as phytate is largely distributed in the aleurone and pericarp layer (Cheryan 1980, Dost and Tokul 2006), removing those layers results in lower phytate contents, yet does not improve mineral availability (Sanz Penella, Collar, and Haros 2008). 


\section{HEALTH EFFECTS OF WHEAT BRAN AND MODIFIED WHEAT BRAN}

\section{Transit and Stool Output}

Due to its bulking effects, WB improves digestive health by increasing faecal output, decreasing transit time, slowing down gastric emptying, softening stool and preventing constipation (McIntyre et al. 1997).

\section{Effects of coarse wheat bran}

The effects of coarse WB on gastrointestinal parameters have been extensively investigated in animal models and human subjects (Burkitt 1971, Chen et al. 1998, Danjo et al. 2008, Harvey, Pomare, and Heaton 1973, Heller, Rivers, and Hackler 1977, Kirwan et al. 1974, Lewis and Heaton 1997, Payler et al. 1975, Slavin and Marlett 1980, Vuksan et al. 2008). A recent meta-analysis, comprising 65 intervention studies in healthy subjects with wheat fibre demonstrated that every additional gram of wheat fibre per day increases stool weight by $3.7 \mathrm{~g} /$ day, dry stool weight by $0.75 \mathrm{~g} /$ day and stool frequency by 0.004 times/day. Furthermore, gastrointestinal transit time is decreased by $0.78 \mathrm{~h}$ per additional gram of wheat fibre among those subjects with a transit time of more than $48 \mathrm{~h}$ (de Vries, Miller, and Verbeke 2015). A large faecal output has been associated with a low incidence of colonic disorders like constipation and diverticular disease and adequate intake of dietary fibre is considered essential for protection and treatment of these disorders (Burkitt 1971).

\section{Effects of reducing particle size}

Different studies univocally showed that coarse WB is more efficient than WB RPS in increasing faecal output and normalising transit time and should be preferred for laxative purposes (Brodribb and Groves 1978, Heller et al. 1980, Kirwan et al. 1974, Smith, Drummond, and Eastwood 1981) (Table 3). In most studies, these differences between coarse and fine WB were attributed to the higher water holding capacity of coarse WB, 
resulting in soft, bulky stools which can easily pass through the colon (Heller et al. 1980, Kirwan et al. 1974). In healthy subjects, WB supplements with different particle sizes for 1 month did not modify faecal bulk nor faecal water content (Jenkins et al. 1999). In contrast, Stephen and Cummings found a $28 \%$ greater water holding capacity for small particles of WB than for large particles (Stephen and Cummings 1979). These conflicting results may be related to the method used to measure water holding capacity, as shown by Jacobs et al. (Jacobs et al. 2015). The centrifugation technique which is used in most studies likely removes more water surrounding the particles than the dialysis bag technique (Life Sciences Research Office 1987). It is not clear which method most closely approximates conditions in vivo.

\section{Effects of heat treatment}

The effects of cooked WB on stool weight, bowel actions and stool water content are conflicting. In humans, faecal wet and dry weight were increased with a high dose ( $39 \mathrm{~g} /$ day) of heat treated bran (Walters et al. 1975) (Table 3). However, unlike uncooked coarse bran in the same dose, cooked WB (22 g/day) did not affect intestinal transit, wet and dry faecal weight and stool frequency (Wyman et al. 1976). The effects of heat treatment could not be attributed to changes in hydration properties as water retention capacity and chemical composition were not affected after dry heat treatment of WB (Jacobs et al. 2016). Similarly, other heat treatments such as extrusion, extrusion-cooking, steam cooking and autoclaving did not modify the water retention capacity of WB (Caprez et al. 1986, Ralet, Thibault, and Della Valle 1990). Nevertheless, boiling may increase the water absorption capacity due to gelatinisation of starch originating from the residual endosperm attached to the WB rather than to changes in hydration properties of the bran tissues itself (Caprez et al. 1986). 


\section{Serum Lipids and Cardiovascular Disease}

Several prospective epidemiological studies have associated the intake of dietary fibre and especially whole-grain products and brans with a reduction of the risk for CVD (He et al. 2010, Jensen et al. 2004, Ye et al. 2012). Consumption of whole-grain products in a dose exceeding $25 \mathrm{~g} /$ day would reduce the risk for CVD with approximately $15 \%$ (Jensen et al. 2004).

Since the 1950s many studies investigated the effects of WB on serum lipids and cholesterol levels which are generally accepted as risk markers for CVD (Kannel et al. 1971, Manson and Bassuk 2015). In healthy male volunteers consumption of $0.5 \mathrm{~g} \mathrm{WB}$ per $\mathrm{kg}$ body weight per day for 4 weeks significantly reduced total cholesterol levels with $10 \%$ and total serum triglycerides with $24 \%$ (van Berge-Henegouwen et al. 1979). The authors speculated that WB enhanced the faecal fat excretion by binding of cholesterol and bile acids to the dietary fibre present in the small intestine, thereby reducing the available amounts for absorption. Therefore, WB should be consumed simultaneously with meals to maximise this effects (Liebman et al. 1983). In addition, the type and origin of the WB influenced its effects. A daily dose of $26 \mathrm{~g}$ hard red spring WB for 28 to 30 days decreased total cholesterol with $12 \%$ and low density lipoprotein (LDL) cholesterol with $21 \%$, whereas the same dose of soft white WB did not induce any changes (Munoz et al. 1979).

Inhibition of pancreatic lipase activity by WB resulting in less hydrolysis and uptake of triglycerides in the small intestine has been proposed as an alternative mechanism for lowering blood lipids. However, this effect has only been demonstrated in in vitro experiments (Borel et al. 1989, Isaksson, Lundquist, and Ihse 1982a, b, Lairon et al. 1985, Vigne et al. 1987). 
Finally, WB extracts in vitro reduced tissue damage by absorbing oxygen radicals formed during lipid peroxidation in LDL cholesterol (Yu, Zhou, and W Parry 2005). In this way, WB might prevent early development of atherosclerosis.

Nevertheless, interventions with WB for several weeks or months in rats on a high-fat, low-fibre diet or rats fed cholesterol (Arvanitakis et al. 1977, Chen and Anderson 1979, Mathe et al. 1977, Truswell and Kay 1976, Tsai et al. 1976, Weber and Kerr 2012), healthy human subjects (Connell and Smith 1974, Costabile et al. 2008, Durrington, Wicks, and Heaton 1975, Eastwood et al. 1973, Heaton, Manning, and Hartog 1976, Jenkins, Hill, and Cummings 1975, Munoz et al. 1979, Persson et al. 1975, Truswell and Kay 1976) and patients suffering from hypercholesterolemia, obesity and type 2 diabetes (Anderson et al. 1991, Bremner et al. 1975, Jenkins et al. 2002, Kestin et al. 1990, Liebman et al. 1983) did not reduce blood lipids, whereas interventions with more soluble dietary fibre sources like oat bran resulted in lower plasma total cholesterol and LDL cholesterol concentrations (Kashtan et al. 1992, Kestin et al. 1990).

Only one study compared the effects of coarse WB and WB RPS $(50 \mu \mathrm{m}, 19 \mathrm{~g} / \mathrm{d})$ on blood total cholesterol and triglyceride levels in hyperlipidemic and healthy subjects. It was hypothesised that WB with finer particle size may be more efficient in reducing serum cholesterol because of its higher surface area for cholesterol and bile acid binding (Jenkins et al. 1999). Unfortunately, a daily dose of neither coarse WB nor WB RPS affected total cholesterol, LDL or high density lipoprotein cholesterol levels.

\section{Colorectal Cancer}

Epidemiological studies have suggested that dietary factors such as fibre and fat intake play a role in colon carcinogenesis (Burkitt 1971, Reddy et al. 1978). Lupton and Turner described four putative mechanisms by which WB might protect against colorectal tumour development (Lupton and Turner 1999). First, (pro)carcinogens and known tumour 
promotors such as bile acids and ammonia are diluted in a bulky stool, reducing their access to the colonic mucosa. In rats, WB diluted a non-absorbable biomarker in all colonic regions to a larger extent than the same amounts of pectin, guar gum, oat bran or cellulose (Gazzaniga and Lupton 1987). Second, acceleration of the intestinal transit by WB leads to a shorter exposure of the luminal contents to the colonic epithelial cells (Lupton and Meacher 1988). A third mechanism relates to the fermentation of WB into SCFA as mainly butyrate inhibits cell proliferation and stimulates differentiation and apoptosis of colonocytes (Boffa et al. 1992, Conway et al. 1995, Gamet et al. 1992, Hague, Butt, and Paraskeva 1996). Lastly, the presence of phytochemicals and the high amounts of phytate in WB have been suggested to protect against tumorigenesis, although these effects have only been minimally investigated. For example, the phytochemical $\beta$-sitosterol, a phytoestrogen, binds to the nuclear estrogen receptor in colonocytes which in turn activates transcription of a tumour suppressor gene (Issa et al. 1994, Waliszewski et al. 1997). Furthermore, high levels of phytate block PI-3 kinase activation in JB6 mouse epidermal cells, a model system for the in vitro analysis of promotion prevention agents, which resulted in an acceleration of apoptosis. However, this effect has not yet been explored in colonocytes (Huang et al. 1997).

\section{Effects of coarse WB}

Most studies investigated the impact of WB on chemically induced colon cancer in rats. Subcutaneous administration of carcinogens such as 1,2-dimethylhydrazine and azoxymethane to rats induces colonic mucosal hyperplasia, a larger proliferation zone, increased distal colonic crypt cell production and shortening of the cell cycle (Jacobs 1983, Sunter, Watson, and Appleton 1981). Although the study designs are quite consistent amongst these studies (diet containing 15-20\% of WB for 20 to 40 weeks and carcinogen administered subcutaneously for 8 to 13 weeks), the observed results are contradictory (Table 4). In some studies benign and malignant colonic tumours were significantly reduced 
when WB was administered. This protective effect was attributed to increased faecal bulk and decreased transit time upon consumption of WB and to the direct adsorption of the carcinogen by WB (Alabaster, Tang, and Shivapurkar 1996, Barnes et al. 1983, Reddy and Mori 1981, Watanabe et al. 1979, Wilson, Hutcheson, and Wideman 1977). Other studies were not able to demonstrate any protective effect of WB compared to a fibre-free diet (Bauer et al. 1979) and in one study WB consumption even increased the number of chemically induced tumours (Jacobs 1983).

In humans, the effect of coarse WB was mainly investigated in patients with a history of CRC (Table 4). Two studies evaluated the impact of WB consumption on mucosal cell proliferation in rectal biopsies. Therefore, biopsies obtained before and after WB consumption were incubated with ${ }^{3} \mathrm{H}$-labelled thymidine. Incorporation of this DNAprecursor into cellular DNA is a marker of cell proliferation (Alberts et al. 1990, Alberts et al. 1997). Two other studies investigated the impact of WB consumption on the recurrence of adenomatous polyps, precursor lesions of colon cancer, in subjects with a history of CRC (DeCosse, Miller, and Lesser 1989, MacLennan et al. 1995). WB consumption only showed very limited or no effects in those human trials. However, these end points rather reflect CRC development than prevention of tumour induction as shown in the rat studies which might explain the discrepancy between rat and human studies.

To what extent production of SCFA such as butyrate contributes to a protective effect against CRC remains to be elucidated. In rats fed WB after 1,2-dimethylhydrazine injection faecal butyrate levels were negatively correlated with tumour mass. (McIntyre, Gibson, and Young 1993). Surprisingly, in another study with a similar design, rats fed WB had significantly lower tumour incidence and lower concentrations of butyrate in the proximal and distal colon (Zoran et al. 1997). 
Total SCFA production increased to a similar extent after in vitro incubation of WB with faecal samples from patients with colonic adenomas, patients with CRC and healthy subjects. The proportion of butyrate was, however, lower in patients with colonic cancer and adenomas compared to healthy controls (Clausen, Bonnen, and Mortensen 1991).

\section{Effects of aleurone-rich bran}

Only a few studies addressed the potential benefits of isolated aleurone on CRC. Supplementation of wheat aleurone (33 g/100 g feed) or coarse WB (16 g/100 g feed) to the diet of azoxymethane-treated rats tended to reduce colon adenomas with $43 \%$ compared to the control cellulose diet (McIntosh, Royle, and Pointing 2001) (Table 4). Faecal butyrate concentrations increased to a similar extent by wheat aleurone and coarse WB suggesting an association between butyrate concentrations and reduced colon adenomas, independent of the bulking effect.

In vitro fermentation of wheat aleurone with faeces induced two- to threefold higher SCFA concentrations than unsupplemented faeces and reduced levels of secondary bile acids, which are considered as tumour promotors (Borowicki et al. 2011, ${ }^{b}$ Borowicki et al. 2010,

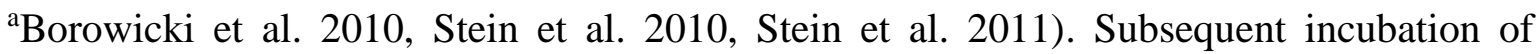
fermentation supernatants with human adenocarcinoma HT29-cells stimulated apoptosis and cell differentiation (Borowicki et al. 2011, ${ }^{\mathrm{b}}$ Borowicki et al. 2010, ${ }^{\mathrm{a} B}$ Borowicki et al. 2010). Furthermore, DNA damage by $\mathrm{H}_{2} \mathrm{O}_{2}$ was significantly reduced in those cells. Also the expression of enzymes involved in antioxidative defence and detoxification of carcinogens in epithelial tissue from healthy colon was increased. Altogether, those results suggest that wheat aleurone may be useful in the prevention of CRC.

\section{Obesity}

Epidemiological studies indicate that a high fibre intake is associated with a lower body weight (Clark and Slavin 2013, Slavin 2005). Different mechanisms have been proposed to 
explain the effects of fibre on body weight and food intake (Heaton 1973). Fibre replaces calories and nutrients from the diet and reduces the energy density of foods. In the proximal gastrointestinal tract, it increases chewing, which limits food intake by promoting the secretion of saliva and gastric juice, leading in turn to accommodation of the stomach and induction of satiety. Upon fermentation by the gut bacteria, SCFA are produced which regulate food intake and nutrient absorption by stimulating the secretion of the satiety hormones glucagon-like peptide 1 and peptide YY (Canfora, Jocken, and Blaak 2015, Drucker 2002). Furthermore, the bulking and viscous properties of dietary fibre also contribute to increased satiety (Burton-Freeman 2000).

In healthy subjects, acute administration of coarse WB with a test meal increased feelings of fullness and satiety, decreased the rate of hunger return and resulted in a significantly lower energy intake during a subsequent ad libitum meal or during the rest of the day (Holt et al. 1999, Samra and Anderson 2007). In contrast, other studies did not observe changes in food intake $2 \mathrm{~h}$ after ingestion of a test meal containing WB despite significantly increased fullness and satiety and decreased hunger and prospective food consumption (Freeland, Anderson, and Wolever 2009, Vuholm et al. 2014). A systematic review on the effect of fibre on satiety and food intake concluded that most acute fibre treatments did not enhance satiety and did not reduce food intake (Clark and Slavin 2013).

The potential role of WB in weight reduction and weight maintenance has been evaluated in animals. In mice fed a high-fat diet for 2 weeks supplementation with $10 \%$ coarse WB or $10 \%$ aleurone did not affect $\mathrm{BW}$, food intake and adipose tissue weights compared to the control diet (Neyrinck et al. 2008). Similarly, addition of $13 \%$ aleurone, aleurone with reduced particle size or xylanase-treated aleurone to the diet of obese mice did not reduce body weight gain and adiposity. Aleurone with reduced particle size even significantly increased BW gain. This can be explained by the fact that grinding increased the aleurone 
particle surface area exposed to digestive enzymes, rendering the digestion more efficient. Enrichment of the diet with xylanase-treated aleurone, in contrast, tended to lower body weight gain and visceral adipose tissue accumulation, which might be attributed to the high proportion of soluble AX in this fraction (Rosa et al. 2014).

Finally, in hamsters on a hypercholesterolemia- and obesity-inducing diet, addition of $10 \%$ HT-WB but not coarse WB for 28 days reduced fat mass and increased lean body mass compared to controls, despite no effect on food intake and weight gain (Harding et al. 2014). This suggests that the compositional changes in the HT-WB, specifically solubility of phenolic antioxidants and fibre, may have contributed to the lower fat accumulation in the animals. However further studies are needed to determine the exact mechanism behind this increased lipolysis or reduced lipogenesis and energy utilization from adipose tissue.

\section{CONCLUSIONS}

Most epidemiological studies provide evidence that consumption of coarse WB is associated with health benefits such as an increased faecal output, normalisation of the gastrointestinal transit and less constipation as parameters for gastrointestinal health and a decreased risk of developing CRC and CVD (Stevenson et al. 2012). Several mechanisms have been proposed to explain these health effects (Figure 3). In addition to the bulking capacities of WB, the production of SCFA and the antioxidant capacity and phytate content of WB may also contribute to the observed health effects. The relative importance of those mechanisms is not known, and may differ for each health benefit.

WB has been mainly modified to improve its technological properties such as its behaviour in the process of bread making. However, modifying WB may also affect health properties. The type of WB modification strongly determines whether the benefits observed with coarse WB are enhanced or attenuated. Modifications that result in a better accessibility of fermentable material, such as WB RPS or aleurone-rich WB, stimulate SCFA production, 
which may protect against CRC. In addition, these fractions contain higher levels of phenolic compounds, leading to increased antioxidant capacity and a lower risk for developing CVD. Reducing the particle size of WB usually decreases water holding capacity and faecal bulking resulting in less effects on gastrointestinal health. Pericarp-rich WB, in contrast, mainly contains unfermentable material, and may result in high bulking effects and an improved gastrointestinal health. However, no human studies have been performed so far. Heat treatment has also been shown to increase faecal bulking and total phenolic content of the WB, yet the mechanism behind it is less clear.

In general, WB modification does not negatively influence the health effects obtained by coarse WB except from a less pronounced effect on faecal bulking. However, most evidence comes from in vitro studies and animals models and still needs to be confirmed in humans, preferably in randomized placebo-controlled intervention studies. In addition, some health effects require higher doses of modified WB compared to coarse WB.

Long-term human intervention studies with modified WB are highly warranted to determine the optimal dose and administration period of WB and to provide more evidence that WB modification is an efficient tool to further improve health effects obtained by the consumption of coarse WB. Nevertheless, it is clear that one "optimal" WB fraction, improving all health effects, does not exist. Depending on the benefit that is aimed for, different WB modifications should be considered to accomplish that specific goal. 


\section{REFERENCES}

Adiotomre, J., M. A. Eastwood, C. A. Edwards, and W. G. Brydon. 1990. Dietary fiber: in vitro methods that anticipate nutrition and metabolic activity in humans. Am J Clin Nutr 52 (1):128-34.

Alabaster, O., Z. Tang, and N. Shivapurkar. 1996. Dietary fiber and the chemopreventive modelation of colon carcinogenesis. Mutat Res 350 (1):185-97.

Alberts, D. S., J. Einspahr, S. Rees-McGee, P. Ramanujam, M. K. Buller, L. Clark, C. Ritenbaugh, J. Atwood, P. Pethigal, D. Earnest, and et al. 1990. Effects of dietary wheat bran fiber on rectal epithelial cell proliferation in patients with resection for colorectal cancers. J Natl Cancer Inst 82 (15):1280-5.

Alberts, D. S., J. Einspahr, C. Ritenbaugh, M. Aickin, S. Rees-McGee, J. Atwood, S. Emerson, N. Mason-Liddil, L. Bettinger, J. Patel, S. Bellapravalu, P. S. Ramanujam, J. Phelps, and L. Clark. 1997. The effect of wheat bran fiber and calcium supplementation on rectal mucosal proliferation rates in patients with resected adenomatous colorectal polyps. Cancer Epidemiol Biomarkers Prev 6 (3):161-9.

Amrein, Thomas M., Peter Gränicher, Eva Arrigoni, and Renato Amadò. 2003. In vitro digestibility and colonic fermentability of aleurone isolated from wheat bran. $L W T$ Food Sci tech 36 (4):451-460. doi: http://dx.doi.org/10.1016/S0023-6438(03)00036-7.

Anderson, J. W., N. H. Gilinsky, D. A. Deakins, S. F. Smith, D. S. O'Neal, D. W. Dillon, and P. R. Oeltgen. 1991. Lipid responses of hypercholesterolemic men to oat-bran and wheat-bran intake. Am J Clin Nutr 54 (4):678-83.

Andersson, Annica A.M., R. Andersson, Anette Jonsäll, Jörgen Andersson, and Helena Fredriksson. 2017. Effect of Different Extrusion Parameters on Dietary Fiber in Wheat Bran and Rye Bran. J Food Sci 82 (6):1344-1350. doi: doi:10.1111/1750-3841.13741. 
Andreasen, M. F., P. A. Kroon, G. Williamson, and M. T. Garcia-Conesa. 2001. Intestinal release and uptake of phenolic antioxidant diferulic acids. Free Radic Biol Med 31 (3):304-14.

Arvanitakis, C., C. L. Stamnes, J. Folscroft, and P. Beyer. 1977. Failure of bran to alter dietinduced hyperlipidemia in the rat. Proc Soc Exp Biol Med 154 (4):550-2.

Bach Knudsen, K. E., Sanna Steenfeldt, C. F. Børsting, and B. O. Eggum. 1995. The nutritive value of decorticated mill fractions of wheat. 1. Chemical composition of raw and enzyme treated fractions and balance experiments with rats. Anim Feed Sci Technol 52 (3-4):205-225. doi: http://dx.doi.org/10.1016/0377-8401(94)00731-N.

Barnes, D. S., N. K. Clapp, D. A. Scott, D. L. Oberst, and S. G. Berry. 1983. Effects of wheat, rice, corn, and soybean bran on 1,2-dimethylhydrazine-induced large bowel tumorigenesis in F344 rats. Nutr Cancer 5 (1):1-9. doi: 10.1080/01635588309513772.

Barron, C., A. Surget, and X. Rouau. 2007. Relative amounts of tissues in mature wheat (Triticum aestivum L.) grain and their carbohydrate and phenolic acid composition. $J$ Cereal Sci 45:88-96.

Bauer, H. G., N. G. Asp, R. Oste, A. Dahlqvist, and P. E. Fredlund. 1979. Effect of dietary fiber on the induction of colorectal tumors and fecal beta-glucuronidase activity in the rat. Cancer Res 39 (9):3752-6.

Boffa, L. C., J. R. Lupton, M. R. Mariani, M. Ceppi, H. L. Newmark, A. Scalmati, and M. Lipkin. 1992. Modulation of colonic epithelial cell proliferation, histone acetylation, and luminal short chain fatty acids by variation of dietary fiber (wheat bran) in rats. Cancer Res 52 (21):5906-12.

Borel, P., D. Lairon, M. Senft, M. Chautan, and H. Lafont. 1989. Wheat bran and wheat germ: effect on digestion and intestinal absorption of dietary lipids in the rat. Am J Clin Nutr 49 (6):1192-202. 
${ }^{\text {a} B o r o w i c k i, ~ A ., ~ A . ~ M i c h e l m a n n, ~ K . ~ S t e i n, ~ D . ~ S c h a r l a u, ~ K . ~ S c h e u, ~ U . ~ O b s t, ~ a n d ~ M . ~ G l e i . ~} 2011$. Fermented wheat aleurone enriched with probiotic strains LGG and Bb12 modulates markers of tumor progression in human colon cells. Nutr Cancer 63 (1):151-60. doi: $10.1080 / 01635581.2010 .516874$.

${ }^{\text {b} B o r o w i c k i, ~ A ., ~ K . ~ S t e i n, ~ D . ~ S c h a r l a u, ~ a n d ~ M . ~ G l e i . ~ 2010 . ~ F e r m e n t a t i o n ~ s u p e r n a t a n t s ~ o f ~ w h e a t ~}$ ( Triticum aestivum L.) aleurone beneficially modulate cancer progression in human colon cells. J Agric Food Chem 58 (3):2001-7. doi: 10.1021/jf9032848.

Borowicki, A., K. Stein, D. Scharlau, K. Scheu, G. Brenner-Weiss, U. Obst, J. Hollmann, M. Lindhauer, N. Wachter, and M. Glei. 2010. Fermented wheat aleurone inhibits growth and induces apoptosis in human HT29 colon adenocarcinoma cells. Br J Nutr 103 (3):360-9. doi: 10.1017/s0007114509991899.

Bremner, W. F., P. M. Brooks, J. L. Third, and T. D. Lawrie. 1975. Bran in hypertriglyceridaemia: a failure of response. $\mathrm{Br} M e d J 3$ (5983):574.

Brewer, L. R., J. Kubola, S. Siriamornpun, T. J. Herald, and Y. C. Shi. 2014. Wheat bran particle size influence on phytochemical extractability and antioxidant properties. Food Chem 152:483-90. doi: 10.1016/j.foodchem.2013.11.128.

Brinch-Pedersen, H., L. D. Sorensen, and P. B. Holm. 2002. Engineering crop plants: getting a handle on phosphate. Trends Plant Sci 7 (3):118-25.

Brodribb, A. J., and C. Groves. 1978. Effect of bran particle size on stool weight. Gut 19 (1):603.

Brouns, F., Y. Hemery, R. Price, and N. M. Anson. 2012. Wheat aleurone: separation, composition, health aspects, and potential food use. Crit Rev Food Sci Nutr 52 (6):55368. doi: 10.1080/10408398.2011.589540. 
Buchanan, C.J., G. Wallace, and S.C. Fry. 1996. In Vivo Release of 14C-Labelled Phenolic Groups from Intact Dietary Spinach Cell Walls During Passage Through the Rat Intestine. J Sci Food Agric 71:459-469.

Burkitt, D. P. 1971. Epidemiology of cancer of the colon and rectum. Cancer 28 (1):3-13.

Burton-Freeman, B. 2000. Dietary fiber and energy regulation. J Nutr 130 (2S Suppl):272S275 S.

Canfora, E. E., J. W. Jocken, and E. E. Blaak. 2015. Short-chain fatty acids in control of body weight and insulin sensitivity. Nat Rev Endocrinol 11 (10):577-91. doi: 10.1038/nrendo.2015.128.

Cani, P. D., A. Everard, and T. Duparc. 2013. Gut microbiota, enteroendocrine functions and metabolism. Curr Opin Pharmacol 13 (6):935-40. doi: 10.1016/j.coph.2013.09.008.

Caprez, Andrea, Eva Arrigoni, Renato Amadò, and Hans Neukom. 1986. Influence of different types of thermal treatment on the chemical composition and physical properties of wheat bran. J Cereal Sci 4 (3):233-239. doi: http://dx.doi.org/10.1016/S0733-5210(86)80025$\mathrm{X}$.

Cheli, F., L. Pinotti, M. Novacco, M. Ottoboni, M. Tretola, and V. Dell'Orto. 2017. Mycotoxins in Wheat and Mitigations Measures. In Wheat Improvement, Management and Utilization., ed. R. Wanyera and J. Owuoche, 39-57. London: InTech.

Chen, H. L., V. S. Haack, C. W. Janecky, N. W. Vollendorf, and J. A. Marlett. 1998. Mechanisms by which wheat bran and oat bran increase stool weight in humans. Am J Clin Nutr 68 (3):711-9.

Chen, W. J., and J. W. Anderson. 1979. Effects of guar gum and wheat bran on lipid metabolism of rats. J Nutr 109 (6):1028-34. 
Cheng, B. O., R. P. Trimble, R. J. Illman, B. A. Stone, and D. L. Topping. 1987. Comparative effects of dietary wheat bran and its morphological components (aleurone and pericarpseed coat) on volatile fatty acid concentrations in the rat. Br J Nutr 57 (1):69-76.

Cheryan, M. 1980. Phytic acid interactions in food systems. Crit Rev Food Sci Nutr 13 (4):297335. doi: 10.1080/10408398009527293.

Clark, M. J., and J. L. Slavin. 2013. The effect of fiber on satiety and food intake: a systematic review. J Am Coll Nutr 32 (3):200-11. doi: 10.1080/07315724.2013.791194.

Clausen, M. R., H. Bonnen, and P. B. Mortensen. 1991. Colonic fermentation of dietary fibre to short chain fatty acids in patients with adenomatous polyps and colonic cancer. Gut $32(8): 923-8$.

Connell, A.M., and C.L. Smith. 1974. The effect of dietary fibre on transit time. In Proceedings of the Fourth International Symposium on Gastrointestinal Motility, 365-368. Vancouver: Mitchell Press.

Conway, R. M., M. C. Madigan, P. L. Penfold, and F. A. Billson. 1995. Induction of apoptosis by sodium butyrate in the human Y-79 retinoblastoma cell line. Oncol Res 7 (6):28997.

Cook, J. D., N. L. Noble, T. A. Morck, S. R. Lynch, and S. J. Petersburg. 1983. Effect of fiber on nonheme iron absorption. Gastroenterology 85 (6):1354-8.

Costabile, A., A. Klinder, F. Fava, A. Napolitano, V. Fogliano, C. Leonard, G. R. Gibson, and K. M. Tuohy. 2008. Whole-grain wheat breakfast cereal has a prebiotic effect on the human gut microbiota: a double-blind, placebo-controlled, crossover study. Br J Nutr 99 (1):110-20. doi: 10.1017/s0007114507793923.

Cummings, J. H., E. R. Beatty, S. M. Kingman, S. A. Bingham, and H. N. Englyst. 1996. Digestion and physiological properties of resistant starch in the human large bowel. $\mathrm{Br}$ J Nutr 75 (5):733-47. 
Cummings, J. H., S. A. Bingham, K. W. Heaton, and M. A. Eastwood. 1992. Fecal weight, colon cancer risk, and dietary intake of nonstarch polysaccharides (dietary fiber). Gastroenterology 103 (6):1783-9.

Cummings, J. H., E. W. Pomare, W. J. Branch, C. P. Naylor, and G. T. Macfarlane. 1987. Short chain fatty acids in human large intestine, portal, hepatic and venous blood. Gut 28 (10):1221-7.

D'hoe, K., L. Conterno, F. Fava, G. Falony, S. Vieira-Silva, J. Vermeiren, K. M. Tuohy, and J. Raes. 2018. Prebiotic wheat bran fractions induce specific microbiota changes. Front Microbiol 9 (31). doi: https://doi.org/10.3389/fmicb.2018.00031.

Danjo, K., J. Sakamoto, S. Iwane, K. Tamura, S. Nakaji, S. Fukuda, H. Murakami, T. Shimoyama, I. Takahashi, and T. Umeda. 2008. Effects of cellulose supplementation on fecal consistency and fecal weight. Dig Dis Sci 53 (3):712-8. doi: 10.1007/s10620-0079938-6.

De Almeida, J.L., B. Pareyt, L.R. Gerits, and J. A. Delcour. 2014. Effect of wheat grain steaming and washing on lipase activity in whole grain flower Cereal Chem 91 (4):321326.

de Kock, S., J. Taylor, and J.R.N. Taylor. 1999. Effect of heat treatment and particle size of different brans on loaf volume of brown bread. LWT - Food Sci tech 32:349-356.

de Vries, J., A. Birkett, T. Hulshof, K. Verbeke, and K. Gibes. 2016. Effects of Cereal, Fruit and Vegetable Fibers on Human Fecal Weight and Transit Time: A Comprehensive Review of Intervention Trials. Nutrients 8 (3):130. doi: 10.3390/nu8030130.

de Vries, J., P. E. Miller, and K. Verbeke. 2015. Effects of cereal fiber on bowel function: A systematic review of intervention trials. World J Gastroenterol 21 (29):8952-63. doi: 10.3748/wjg.v21.i29.8952. 
DeCosse, J. J., H. H. Miller, and M. L. Lesser. 1989. Effect of wheat fiber and vitamins C and E on rectal polyps in patients with familial adenomatous polyposis. $J$ Natl Cancer Inst $81(17): 1290-7$.

Delcour, J. A., and R.C. Hoseney. 2010. Principles of Cereal Science and Technology. 3 ed. Minnesota, U.S.A.: AACC International, Inc.

Deroover, L., J. Verspreet, A. Luypaerts, G. Vandermeulen, C. M. Courtin, and K. Verbeke. 2017. Wheat Bran Does Not Affect Postprandial Plasma Short-Chain Fatty Acids from 13C-inulin Fermentation in Healthy Subjects. Nutrients 9 (1). doi: 10.3390/nu9010083.

Dexter, J.E., and P.J. Wood. 1996. Recent applications of debranning of wheat before milling. Trends Food Sci Technol 7:35-41.

Dobbs, R. J., and I. M. Baird. 1977. Effect of wholemeal and white bread on iron absorption in normal people. $\mathrm{Br}$ Med J 1 (6077):1641-2.

Dost, Kenan, and Ozge Tokul. 2006. Determination of phytic acid in wheat and wheat products by reverse phase high performance liquid chromatography. Anal Chim Acta 558 (12):22-27. doi: http://dx.doi.org/10.1016/j.aca.2005.11.035.

Douge, M., M. Nonus, T. Thomasset, P. Teissier, and J. Barbeau. 2004. ESEM Study of the Effects of Hydrolytic Enzymes on Wheat bran Structure. Microscopy and Analysis 18 (6):21-22.

Drucker, D. J. 2002. Biological actions and therapeutic potential of the glucagon-like peptides. Gastroenterology 122 (2):531-44.

Duncan, S. H., W. R. Russell, A. Quartieri, M. Rossi, J. Parkhill, A. W. Walker, and H. J. Flint. 2015. Wheat bran promotes enrichment within the human colonic microbiota of butyrate-producing bacteria that release ferulic acid. Environ Microbiol 18 (7):22142225. doi: 10.1111/1462-2920.13158. 
Durrington, P., A. C. Wicks, and K. W. Heaton. 1975. Letter: Effect of bran on blood-lipids. Lancet 2 (7925):133.

Eastwood, M. A., J. R. Kirkpatrick, W. D. Mitchell, A. Bone, and T. Hamilton. 1973. Effects of dietary supplements of wheat bran and cellulose on faeces and bowel function. $\mathrm{Br}$ Med J 4 (5889):392-4.

Eastwood, M. A., J. A. Robertson, W. G. Brydon, and D. MacDonald. 1983. Measurement of water-holding properties of fibre and their faecal bulking ability in man. Br J Nutr 50 (3):539-47.

Ehle, F. R., J. B. Robertson, and P. J. Van Soest. 1982. Influence of dietary fibers on fermentation in the human large intestine. J Nutr 112 (1):158-66.

European Flour Millers. 2016. European Flour Milling Industry. Accessed Jan 16. http://www.flourmillers.eu/.

Fincher, GB, and B.A. Stone. 1986. Cell walls and their components in cereal grain technology. In Advances in Cereal Science and Technology, ed. Y. Pomeranz, 207-295. St Paul, MN: American Association of Cereal Chemists.

Fleming, S. E., M. D. Fitch, and M. W. Chansler. 1989. High-fiber diets: influence on characteristics of cecal digesta including short-chain fatty acid concentrations and $\mathrm{pH}$. Am J Clin Nutr 50 (1):93-9.

Fly, Alyce D., and Gail L. Czarnecki-Maulden. 1996. Iron bioavailability from diets containing high-fiber breakfast cereals and crackers. Nutr Res 16 (2):267-278. doi: http://dx.doi.org/10.1016/0271-5317(96)00011-5.

Freeland, K. R., G. H. Anderson, and T. M. Wolever. 2009. Acute effects of dietary fibre and glycaemic carbohydrate on appetite and food intake in healthy males. Appetite 52 (1):58-64. doi: 10.1016/j.appet.2008.08.001. 
Gamet, L., D. Daviaud, C. Denis-Pouxviel, C. Remesy, and J. C. Murat. 1992. Effects of shortchain fatty acids on growth and differentiation of the human colon-cancer cell line HT29. Int J Cancer 52 (2):286-9.

Gazzaniga, Jeanne M., and Joanne R. Lupton. 1987. Dilution effect of dietary fiber sources: An in vivo study in the rat. Nutr Res 7 (12):1261-1268. doi: http://dx.doi.org/10.1016/S0271-5317(87)80086-6.

Gélinas, Pierre, and Carole M. McKinnon. 2006. Effect of wheat variety, farming site, and bread-baking on total phenolics. Int J Food Sci Technol 41 (3):329-332. doi: 10.1111/j.1365-2621.2005.01057.x.

Govers, M. J., N. J. Gannon, F. R. Dunshea, P. R. Gibson, and J. G. Muir. 1999. Wheat bran affects the site of fermentation of resistant starch and luminal indexes related to colon cancer risk: a study in pigs. Gut 45 (6):840-7.

Hague, A., A. J. Butt, and C. Paraskeva. 1996. The role of butyrate in human colonic epithelial cells: an energy source or inducer of differentiation and apoptosis? Proc Nutr Soc 55 (3):937-43.

Hallfrisch, J., and K. M. Behall. 1999. Breath hydrogen and methane responses of men and women to breads made with white flour or whole wheat flours of different particle sizes. J Am Coll Nutr 18 (4):296-302.

Harding, S. V., H. D. Sapirstein, T. C. Rideout, C. P. Marinangeli, A. K. Dona, and P. J. Jones. 2014. Consumption of wheat bran modified by autoclaving reduces fat mass in hamsters. Eur J Nutr 53 (3):793-802. doi: 10.1007/s00394-013-0583-x.

Harland, B. F., and D. Oberleas. 1987. Phytate in foods. World Rev Nutr Diet 52:235-59.

Harvey, R. F., E. W. Pomare, and K. W. Heaton. 1973. Effects of increased dietary fibre on intestinal transit. Lancet 1 (7815):1278-80. 
He, M., R. M. van Dam, E. Rimm, F. B. Hu, and L. Qi. 2010. Whole-grain, cereal fiber, bran, and germ intake and the risks of all-cause and cardiovascular disease-specific mortality among women with type 2 diabetes mellitus. Circulation 121 (20):2162-8. doi: 10.1161/circulationaha.109.907360.

Heaton, K. W. 1973. Food fibre as an obstacle to energy intake. Lancet 2 (7843):1418-21.

Heaton, K. W., A. P. Manning, and M. Hartog. 1976. Lack of effect on blood lipid and calcium concentrations of young men on changing from white to wholemeal bread. Br J Nutr 35 (1):55-60.

Heller, S. N., L. R. Hackler, J. M. Rivers, P. J. Van Soest, D. A. Roe, B. A. Lewis, and J. Robertson. 1980. Dietary fiber: the effect of particle size of wheat bran on colonic function in young adult men. Am J Clin Nutr 33 (8):1734-44.

Heller, S.N., J. M. Rivers, and L.R. Hackler. 1977. Dietary fiber: The effect of particle size and pH on its measurement. J Food Sci 42:436.

Hemery, Y., X. Rouau, C. Dragan, M. Bilici, R. Beleca, and L. Dascalescu. 2009. Electrostatic properties of wheat bran and its constitutive layers: Influence of particle size, composition, and moisture content. J Food Eng 93:114-124.

Hemery, Y., X. Rouau, V. Lullien-Pellerin, C. Barron, and J. Abecassis. 2007. Dry processes to develop wheat fractions and products with enhanced nutritional quality. J Cereal Sci $46(327-347)$.

Hemery, Y.M., N. M. Anson, R. Havenaar, G. R.M.M. Haenen, M.W.J. Noort, and X. Rouau. 2010. Dry fractionation of wheat bran increases the bioaccessibility of phenolic acids. Food Res Int 43:1429-1438.

Henrion, M., M. Servaes, F. Thielecke, and V. Fogliano. 2018. Application of the QUENCHER methodology to the food industry. Food Chem 240:951-958. doi: 10.1016/j.foodchem.2017.07.119. 
Holt, S. H., H. J. Delargy, C. L. Lawton, and J. E. Blundell. 1999. The effects of highcarbohydrate vs high-fat breakfasts on feelings of fullness and alertness, and subsequent food intake. Int J Food Sci Nutr 50 (1):13-28.

Holtekjølen, A. K., A. B. Bævre, M. Rødbotten, H. Berg, and S. H. Knutsen. 2008. Antioxidant properties and sensory profiles of breads containing barley flour. Food Chem 110 (2):414-421. doi: http://dx.doi.org/10.1016/j.foodchem.2008.02.054.

Huang, C., W. Y. Ma, S. S. Hecht, and Z. Dong. 1997. Inositol hexaphosphate inhibits cell transformation and activator protein 1 activation by targeting phosphatidylinositol-3' kinase. Cancer Res 57 (14):2873-8.

Hylla, S., A. Gostner, G. Dusel, H. Anger, H. P. Bartram, S. U. Christl, H. Kasper, and W. Scheppach. 1998. Effects of resistant starch on the colon in healthy volunteers: possible implications for cancer prevention. Am J Clin Nutr 67 (1):136-42.

Isaksson, G., I. Lundquist, and I. Ihse. 1982a. Effect of dietary fiber on pancreatic enzyme activity in vitro. Gastroenterology 82 (5 Pt 1):918-24.

Isaksson, G., I. Lundquist, and I. Ihse. 1982b. In vitro inhibition of pancreatic enzyme activities by dietary fiber. Digestion 24 (1):54-9.

Issa, J. P., Y. L. Ottaviano, P. Celano, S. R. Hamilton, N. E. Davidson, and S. B. Baylin. 1994. Methylation of the oestrogen receptor $\mathrm{CpG}$ island links ageing and neoplasia in human colon. Nat Genet 7 (4):536-40. doi: 10.1038/ng0894-536.

Jacobs, L. R. 1983. Enhancement of rat colon carcinogenesis by wheat bran consumption during the stage of 1,2-dimethylhydrazine administration. Cancer Res 43 (9):4057-61.

Jacobs, P. J., S. Hemdane, J. A. Delcour, and C. M. Courtin. 2016. Dry heat treatment affects wheat bran surface properties and hydration kinetics. Food Chem 203:513-20. doi: 10.1016/j.foodchem.2016.02.062. 
Jacobs, P. J., S. Hemdane, E. Dornez, J. A. Delcour, and C. M. Courtin. 2015. Study of hydration properties of wheat bran as a function of particle size. Food Chem 179:296304. doi: 10.1016/j.foodchem.2015.01.117.

Jenkins, D. J., M. S. Hill, and J. H. Cummings. 1975. Effect of wheat fiber on blood lipids, fecal steroid excretion and serum iron. Am J Clin Nutr 28 (12):1408-11.

Jenkins, D. J., C. W. Kendall, L. S. Augustin, M. C. Martini, M. Axelsen, D. Faulkner, E. Vidgen, T. Parker, H. Lau, P. W. Connelly, J. Teitel, W. Singer, A. C. Vandenbroucke, L. A. Leiter, and R. G. Josse. 2002. Effect of wheat bran on glycemic control and risk factors for cardiovascular disease in type 2 diabetes. Diabetes Care 25 (9):1522-8.

Jenkins, D. J., C. W. Kendall, V. Vuksan, L. S. Augustin, Y. M. Li, B. Lee, C. C. Mehling, T. Parker, D. Faulkner, H. Seyler, E. Vidgen, and V. Fulgoni. 1999. The effect of wheat bran particle size on laxation and colonic fermentation. J Am Coll Nutr 18 (4):339-45.

Jenkins, D. J., C. W. Kendall, V. Vuksan, L. S. Augustin, C. Mehling, T. Parker, E. Vidgen, B. Lee, D. Faulkner, H. Seyler, R. Josse, L. A. Leiter, P. W. Connelly, and V. Fulgoni, 3rd. 1999. Effect of wheat bran on serum lipids: influence of particle size and wheat protein. J Am Coll Nutr 18 (2):159-65.

Jensen, M. K., P. Koh-Banerjee, F. B. Hu, M. Franz, L. Sampson, M. Gronbaek, and E. B. Rimm. 2004. Intakes of whole grains, bran, and germ and the risk of coronary heart disease in men. Am J Clin Nutr 80 (6):1492-9.

Kannel, W. B., W. P. Castelli, T. Gordon, and P. M. McNamara. 1971. Serum cholesterol, lipoproteins, and the risk of coronary heart disease. The Framingham study. Ann Intern Med 74 (1):1-12.

Karppinen, Sirpa, Kirsi Liukkonen, Anna-Marja Aura, Pirkko Forssell, and Kaisa Poutanen. 2000. In vitro fermentation of polysaccharides of rye, wheat and oat brans and inulin by 
human faecal bacteria. J Sci Food Agric 80 (10):1469-1476. doi: 10.1002/10970010(200008)80:10<1469::AID-JSFA675>3.0.CO;2-A.

Kashtan, H., H. S. Stern, D. J. Jenkins, A. L. Jenkins, K. Hay, N. Marcon, S. Minkin, and W. R. Bruce. 1992. Wheat-bran and oat-bran supplements' effects on blood lipids and lipoproteins. Am J Clin Nutr 55 (5):976-80.

Kestin, M., R. Moss, P. M. Clifton, and P. J. Nestel. 1990. Comparative effects of three cereal brans on plasma lipids, blood pressure, and glucose metabolism in mildly hypercholesterolemic men. Am J Clin Nutr 52 (4):661-6.

Khan, M. J., K. Gerasimidis, C. A. Edwards, and M. G. Shaikh. 2016. Role of Gut Microbiota in the Aetiology of Obesity: Proposed Mechanisms and Review of the Literature. J Obes 2016:7353642. doi: 10.1155/2016/7353642.

Kirwan, W. O., A. N. Smith, A. A. McConnell, W. D. Mitchell, and M. A. Eastwood. 1974. Action of different bran preparations on colonic function. Br Med J 4 (5938):187-9.

Kraler, M., M. Ghanbari, K. J. Domig, K. Schedle, and W. Kneifel. 2016. The intestinal microbiota of piglets fed with wheat bran variants as characterised by $16 \mathrm{~S}$ rRNA nextgeneration amplicon sequencing. Arch Anim Nutr 70 (3):173-89. doi: 10.1080/1745039x.2016.1160534.

Kroon, Paul A., Craig B. Faulds, Peter Ryden, James A. Robertson, and Gary Williamson. 1997. Release of Covalently Bound Ferulic Acid from Fiber in the Human Colon. J Agric Food Chem 45 (3):661-667. doi: 10.1021/jf9604403.

Kvist, S., T. Carlsson, J.M. Lawther, and F.B. Decastro. 2010. Process for the fractionation of cereal brans.

Lairon, D., H. Lafont, J. L. Vigne, G. Nalbone, J. Leonardi, and J. C. Hauton. 1985. Effects of dietary fibers and cholestyramine on the activity of pancreatic lipase in vitro. Am J Clin Nutr 42 (4):629-38. 
Leenhardt, F., B. Lyan, E. Rock, A. Boussard, J. Potus, E. Chanliaud, and C. Remesy. 2006. Wheat lipoxygenase activity induces greater loss of carotenoids than vitamin $\mathrm{E}$ during breadmaking. J Agric Food Chem 54 (5):1710-5. doi: 10.1021/jf052243m.

Leitch, E. C., A. W. Walker, S. H. Duncan, G. Holtrop, and H. J. Flint. 2007. Selective colonization of insoluble substrates by human faecal bacteria. Environ Microbiol 9 (3):667-79. doi: 10.1111/j.1462-2920.2006.01186.x.

Lewis, S. J., and K. W. Heaton. 1997. Increasing butyrate concentration in the distal colon by accelerating intestinal transit. Gut 41 (2):245-51.

Liebman, M., M. C. Smith, J. Iverson, F. W. Thye, D. E. Hinkle, W. G. Herbert, S. J. Ritchey, and J. A. Driskell. 1983. Effect of coarse wheat bran fiber and exercise on plasma lipids and lipoproteins in moderately overweight men. Am J Clin Nutr 37 (1):71-81.

Life Sciences Research Office. 1987. Physiological Effects and Health Consequences of Dietary Fiber. ed SM Pilch. Washington DC: FDA DHHS.

Liu, Rui Hai. 2007. Whole grain phytochemicals and health. J Cereal Sci 46 (3):207-219. doi: http://dx.doi.org/10.1016/j.jcs.2007.06.010.

Liu, Z. H., H. Y. Wang, X. E. Wang, G. P. Zhang, P. D. Chen, and D. J. Liu. 2007. Phytase activity, phytate, iron, and zinc contents in wheat pearling fractions and their variation across production locations. $J$ Cereal Sci $45 \quad$ (3):319-326. doi: http://doi.org/10.1016/j.jcs.2006.10.004.

Liyana-Pathirana, Chandrika M., and Fereidoon Shahidi. 2007. The antioxidant potential of milling fractions from breadwheat and durum. J Cereal Sci 45 (3):238-247. doi: http://dx.doi.org/10.1016/j.jcs.2006.08.007.

Lupton, J. R., and M. M. Meacher. 1988. Radiographic analysis of the effect of dietary fibers on rat colonic transit time. Am J Physiol 255 (5 Pt 1):G633-9. 
Lupton, J. R., and N. D. Turner. 1999. Potential protective mechanisms of wheat bran fiber. Am $J$ Med 106 (1A):24S-27S.

MacLennan, R., F. Macrae, C. Bain, D. Battistutta, P. Chapuis, H. Gratten, J. Lambert, R. C. Newland, M. Ngu, A. Russell, M. Ward, and M. L. Wahlqvist. 1995. Randomized trial of intake of fat, fiber, and beta carotene to prevent colorectal adenomas. J Natl Cancer Inst 87 (23):1760-6.

Majzoobi, M., S. Pashangeh, A. Farahnaky, M. H. Eskandari, and J. Jamalian. 2014. Effect of particle size reduction, hydrothermal and fermentation treatments on phytic acid content and some physicochemical properties of wheat bran. J Food Sci Technol 51 (10):275561. doi: 10.1007/s13197-012-0802-0.

Manach, C., A. Scalbert, C. Morand, C. Remesy, and L. Jimenez. 2004. Polyphenols: food sources and bioavailability. Am J Clin Nutr 79 (5):727-47.

Manini, F., M. Brasca, C. Plumed-Ferrer, S. Morandi, D. Erba, and M.C. Casiraghi. 2014. Study of the chemical changes and evolution of microbiota during sourdoughlike fermentation of wheat bran. Cereal Chem 91 (4):342-349.

Manson, J. E., and S. S. Bassuk. 2015. Biomarkers of cardiovascular disease risk in women. Metabolism 64 (3 Suppl 1):S33-9. doi: 10.1016/j.metabol.2014.10.028.

Mateo Anson, N., R. van den Berg, R. Havenaar, A. Bast, and G. R. Haenen. 2008. Ferulic acid from aleurone determines the antioxidant potency of wheat grain (Triticum aestivum L.). J Agric Food Chem 56 (14):5589-94. doi: 10.1021/jf800445k.

Mathe, D., C. Lutton, J. Rautureau, T. Coste, E. Gouffier, J. C. Sulpice, and F. Chevallier. 1977. Effects of dietary fiber and salt mixtures on the cholesterol metabolism of rats. $J$ Nutr 107 (3):466-74.

Mathers, J. C., and J. M. Tagny. 1994. Diurnal changes in large-bowel metabolism: short-chain fatty acids and transit time in rats fed on wheat bran. Br J Nutr 71 (2):209-22. 
McBurney, M. I., and L. U. Thompson. 1990. Fermentative characteristics of cereal brans and vegetable fibers. Nutr Cancer 13 (4):271-80. doi: 10.1080/01635589009514069.

McIntosh, G. H., P. J. Royle, and G. Pointing. 2001. Wheat aleurone flour increases cecal betaglucuronidase activity and butyrate concentration and reduces colon adenoma burden in azoxymethane-treated rats. $J$ Nutr 131 (1):127-31.

McIntyre, A., P. R. Gibson, and G. P. Young. 1993. Butyrate production from dietary fibre and protection against large bowel cancer in a rat model. Gut 34 (3):386-91.

McIntyre, A., R. M. Vincent, A. C. Perkins, and R. C. Spiller. 1997. Effect of bran, ispaghula, and inert plastic particles on gastric emptying and small bowel transit in humans: the role of physical factors. Gut 40 (2):223-7.

McIntyre, A., G. P. Young, T. Taranto, P. R. Gibson, and P. B. Ward. 1991. Different fibers have different regional effects on luminal contents of rat colon. Gastroenterology 101 (5):1274-81.

Menga, Valeria, Clara Fares, Antonio Troccoli, Luigi Cattivelli, and Antonietta Baiano. 2010. Effects of genotype, location and baking on the phenolic content and some antioxidant properties of cereal species. Int J Food Sci Technol 45 (1):7-16. doi: 10.1111/j.13652621.2009.02072.x.

Monro, J. A. 2000. Faecal bulking index: A physiological basis for dietary management of bulk in the distal colon. Asia Pac J Clin Nutr 9 (2):74-81.

Monro, J. A. 2001. Wheat bran equivalents based on faecal bulking indices for dietary management of faecal bulk. Asia Pac J Clin Nutr 10 (3):242-8.

Monro, J.A. 2002. New approaches to providing nutrition information. In The nutrition handbook for food processors, ed. C.K.J. Henry and C. Chapman, 165-192. Boca Raton, NC: CRC Press. 
Mosharraf, L., M. Kadivar, and M. Shahedi. 2009. Effect of hydrothermaled bran on physicochemical, rheological and microstructural characteristics of Sangak bread. $J$ Cereal Sci 49:398-404.

Muir, J. G., E. G. Yeow, J. Keogh, C. Pizzey, A. R. Bird, K. Sharpe, K. O'Dea, and F. A. Macrae. 2004. Combining wheat bran with resistant starch has more beneficial effects on fecal indexes than does wheat bran alone. Am J Clin Nutr 79 (6):1020-8.

Munoz, J. M., H. H. Sandstead, R. A. Jacob, G. M. Logan, Jr., S. J. Reck, L. M. Klevay, F. R. Dintzis, G. E. Inglett, and W. C. Shuey. 1979. Effects of some cereal brans and textured vegetable protein on plasma lipids. Am J Clin Nutr 32 (3):580-92.

Nandeesh, K., R. Jyotsna, and G.V. Rao. 2011. Effect of differently treated wheat bran on rheology, microstructure and quality characteristics of soft dough biscuits. J Food Process Preserv 35 (2):179-200.

Neyrinck, A. M., F. De Backer, P. D. Cani, L. B. Bindels, A. Stroobants, D. Portetelle, and N. M. Delzenne. 2008. Immunomodulatory properties of two wheat bran fractions aleurone-enriched and crude fractions - in obese mice fed a high fat diet. Int Immunopharmacol 8 (10):1423-32. doi: 10.1016/j.intimp.2008.05.015.

Noort, M.W.J., D.V. Haaster, Y. Hemery, H.A. Schols, and R.J. Hamer. 2010. The effect of particle size of wheat bran factions on bread quality - evidence for fiber - protein interactions. J Cereal Sci 52:59-64.

Nordlund, E., A. M. Aura, I. Mattila, T. Kosso, X. Rouau, and K. Poutanen. 2012. Formation of phenolic microbial metabolites and short-chain fatty acids from rye, wheat, and oat bran and their fractions in the metabolical in vitro colon model. J Agric Food Chem 60 (33):8134-45. doi: 10.1021/jf3008037.

Payler, D. K., E. W. Pomare, K. W. Heaton, and R. F. Harvey. 1975. The effect of wheat bran on intestinal transit. Gut 16 (3):209-13. 
Perez-Jimenez, J., and F. Saura-Calixto. 2005. Literature data may underestimate the actual antioxidant capacity of cereals. J Agric Food Chem 53 (12):5036-40. doi: 10.1021/jf050049u.

Persson, I., K. Raby, P. Fonns-Bech, and E. Jensen. 1975. Letter: Bran and blood-lipids. Lancet $2(7946): 1208-9$.

Phillips, J., J. G. Muir, A. Birkett, Z. X. Lu, G. P. Jones, K. O'Dea, and G. P. Young. 1995. Effect of resistant starch on fecal bulk and fermentation-dependent events in humans. Am J Clin Nutr 62 (1):121-30.

Price, Ruth K., Robert W. Welch, Alison M. Lee-Manion, Ian Bradbury, and J. J. Strain. 2008. Total Phenolics and Antioxidant Potential in Plasma and Urine of Humans After Consumption of Wheat Bran. Cereal Chem 85 (2):152-157.

Qin, J., R. Li, J. Raes, M. Arumugam, K. S. Burgdorf, C. Manichanh, T. Nielsen, N. Pons, F. Levenez, T. Yamada, D. R. Mende, J. Li, J. Xu, S. Li, D. Li, J. Cao, B. Wang, H. Liang, H. Zheng, Y. Xie, J. Tap, P. Lepage, M. Bertalan, J. M. Batto, T. Hansen, D. Le Paslier, A. Linneberg, H. B. Nielsen, E. Pelletier, P. Renault, T. Sicheritz-Ponten, K. Turner, H. Zhu, C. Yu, S. Li, M. Jian, Y. Zhou, Y. Li, X. Zhang, S. Li, N. Qin, H. Yang, J. Wang, S. Brunak, J. Dore, F. Guarner, K. Kristiansen, O. Pedersen, J. Parkhill, J. Weissenbach, P. Bork, S. D. Ehrlich, and J. Wang. 2010. A human gut microbial gene catalogue established by metagenomic sequencing. Nature 464 (7285):59-65. doi: 10.1038/nature08821.

Ralet, M. C., J. F. Thibault, and G. Della Valle. 1990. Influence of extrusion-cooking on the physico-chemical properties of wheat bran. J Cereal Sci 11 (3):249-259. doi: http://dx.doi.org/10.1016/S0733-5210(09)80169-0. 
Reddy, B. S., A. R. Hedges, K. Laakso, and E. L. Wynder. 1978. Metabolic epidemiology of large bowel cancer: fecal bulk and constituents of high-risk North American and lowrisk Finnish population. Cancer 42 (6):2832-8.

Reddy, B. S., and H. Mori. 1981. Effect of dietary wheat bran and dehydrated citrus fiber on 3,2'-dimethyl-4-aminobiphenyl-induced intestinal carcinogenesis in F344 rats. Carcinogenesis 2 (1):21-5.

Reddy, B. S., H. Mori, and M. Nicolais. 1981. Effect of dietary wheat bran and dehydrated citrus fiber on azoxymethane-induced intestinal carcinogenesis in Fischer 344 rats. $J$ Natl Cancer Inst 66 (3):553-7.

Reddy, N. R., and M. D. Pierson. 1994. Reduction in antinutritional and toxic components in plant foods by fermentationaaThe term 'plant foods' is used in the context of food derived from plant sources. Food Res Int 27 (3):281-290. doi: http://dx.doi.org/10.1016/0963-9969(94)90096-5.

Rondini, L., M. N. Peyrat-Maillard, A. Marsset-Baglieri, and C. Berset. 2002. Sulfated ferulic acid is the main in vivo metabolite found after short-term ingestion of free ferulic acid in rats. J Agric Food Chem 50 (10):3037-41.

Rondini, L., M. N. Peyrat-Maillard, A. Marsset-Baglieri, G. Fromentin, P. Durand, D. Tome, M. Prost, and C. Berset. 2004. Bound ferulic acid from bran is more bioavailable than the free compound in rat. J Agric Food Chem 52 (13):4338-43. doi: 10.1021/jf0348323.

Rosa, N. N., A. M. Aura, L. Saulnier, U. Holopainen-Mantila, K. Poutanen, and V. Micard. 2013. Effects of disintegration on in vitro fermentation and conversion patterns of wheat aleurone in a metabolical colon model. J Agric Food Chem 61 (24):5805-16. doi: $10.1021 / \mathrm{jf} 4001814$. 
Rosa, N. N., C. Barron, C. Gaiani, C. Dufour, and V. Micard. 2013. Ultra-fine grinding increases the antioxidant capacity of wheat bran. J Cereal Sci 57 (1):84-90. doi: http://dx.doi.org/10.1016/j.jcs.2012.10.002.

Rosa, N. N., J. Pekkinen, K. Zavala, G. Fouret, A. Korkmaz, C. Feillet-Coudray, M. Atalay, K. Hanhineva, H. Mykkanen, K. Poutanen, and V. Micard. 2014. Impact of wheat aleurone structure on metabolic disorders caused by a high-fat diet in mice. J Agric Food Chem 62 (41):10101-9. doi: 10.1021/jf503314a.

Ross, A. B., A. Kamal-Eldin, and P. Aman. 2004. Dietary alkylresorcinols: absorption, bioactivities, and possible use as biomarkers of whole-grain wheat- and rye-rich foods. Nutr Rev 62 (3):81-95.

Salonen, A., L. Lahti, J. Salojarvi, G. Holtrop, K. Korpela, S. H. Duncan, P. Date, F. Farquharson, A. M. Johnstone, G. E. Lobley, P. Louis, H. J. Flint, and W. M. de Vos. 2014. Impact of diet and individual variation on intestinal microbiota composition and fermentation products in obese men. ISME $J \quad 8$ (11):2218-30. doi: 10.1038/ismej.2014.63.

Samra, R. A., and G. H. Anderson. 2007. Insoluble cereal fiber reduces appetite and short-term food intake and glycemic response to food consumed 75 min later by healthy men. Am J Clin Nutr 86 (4):972-9.

Sandberg, A. S., C. Hasselblad, K. Hasselblad, and L. Hulten. 1982. The effect of wheat bran on the absorption of minerals in the small intestine. Br J Nutr 48 (2):185-91.

Sanz Penella, J. M., C. Collar, and M. Haros. 2008. Effect of wheat bran and enzyme addition on dough functional performance and phytic acid levels in bread. J Cereal Sci 48 (3):715-721. doi: http://doi.org/10.1016/j.jcs.2008.03.006.

Scheppach, W., C. Fabian, M. Sachs, and H. Kasper. 1988. The effect of starch malabsorption on fecal short-chain fatty acid excretion in man. Scand J Gastroenterol 23 (6):755-9. 
Shenoy, H.A., and Jamuna Prakash. 2002. Wheat bran (Triticum aestivum): Composition, functionality and incorporation in unleavened bread. J Food Qual 25 (3):197-211. doi: 10.1111/j.1745-4557.2002.tb01019.x.

Simpson, K. M., E. R. Morris, and J. D. Cook. 1981. The inhibitory effect of bran on iron absorption in man. Am J Clin Nutr 34 (8):1469-78.

Slavin, J. L. 2005. Dietary fiber and body weight. Nutrition 21 (3):411-8. doi: 10.1016/j.nut.2004.08.018.

Slavin, J. L., and J. A. Marlett. 1980. Influence of refined cellulose on human bowel function and calcium and magnesium balance. Am J Clin Nutr 33 (9):1932-9.

Smith, A. N., E. Drummond, and M. A. Eastwood. 1981. The effect of coarse and fine Canadian Red Spring Wheat and French Soft Wheat bran on colonic motility in patients with diverticular disease. Am J Clin Nutr 34 (11):2460-3.

Stein, K., A. Borowicki, D. Scharlau, and M. Glei. 2010. Fermented wheat aleurone induces enzymes involved in detoxification of carcinogens and in antioxidative defence in human colon cells. Br J Nutr 104 (8):1101-11. doi: 10.1017/s0007114510001881.

Stein, K., A. Borowicki, D. Scharlau, K. Scheu, G. Brenner-Weiss, U. Obst, J. Hollmann, M. Lindhauer, N. Wachter, and M. Glei. 2011. Modification of an in vitro model simulating the whole digestive process to investigate cellular endpoints of chemoprevention. $\mathrm{Br} J$ Nutr 105 (5):678-87. doi: 10.1017/s0007114510004320.

Stephen, A. M., and J. H. Cummings. 1979. Water-holding by dietary fibre in vitro and its relationship to faecal output in man. Gut 20 (8):722-9.

Stevenson, L., F. Phillips, K. O'Sullivan, and J. Walton. 2012. Wheat bran: its composition and benefits to health, a European perspective. Int J Food Sci Nutr 63 (8):1001-13. doi: 10.3109/09637486.2012.687366. 
Stewart, M. L., and J. L. Slavin. 2009. Particle size and fraction of wheat bran influence shortchain fatty acid production in vitro. $B r \quad J \quad$ Nutr 102 (10):1404-7. doi: $10.1017 / \mathrm{s} 0007114509990663$.

Sudha, M. L., P. R. Ramasarma, and G. Venkateswara Rao. 2011. Wheat bran stabilization and its use in the preparation of high-fiber pasta. Food Sci Technol Int 17 (1):47-53. doi: 10.1177/1082013210368463.

Sunter, J. P., A. J. Watson, and D. R. Appleton. 1981. Kinetics of the non-neoplastic mucosa of the large bowel of dimethylhydrazine-treated rats. Br J Cancer 44 (1):35-44.

Topping, D. L. 2007. Cereal complex carbohydrates and their contribution to human health. $J$ Cereal Sci 46:220-229.

Truswell, A. S., and R. M. Kay. 1976. Letter: Bran and blood-lipids. Lancet 1 (7955):367.

Tsai, A. C., J. Elias, J. J. Kelley, R. S. Lin, and J. R. Robson. 1976. Influence of certain dietary fibers on serum and tissue cholesterol levels in rats. $J$ Nutr 106 (1):118-23.

Vaher, Merike, Kersti Matso, Tuuli Levandi, Kati Helmja, and Mihkel Kaljurand. 2010. Phenolic compounds and the antioxidant activity of the bran, flour and whole grain of different wheat varieties. 5th Conference by Nordic Separation Science Society, Talinn, Estonia.

van Berge-Henegouwen, G. P., A. W. Huybregts, S. van de Werf, P. Demacker, and R. W. Schade. 1979. Effect of a standardized wheat bran preparation on serum lipids in young healthy males. Am J Clin Nutr 32 (4):794-8.

van Munster, I. P., A. Tangerman, and F. M. Nagengast. 1994. Effect of resistant starch on colonic fermentation, bile acid metabolism, and mucosal proliferation. Dig Dis Sci 39 (4):834-42. 
Vigne, J. L., D. Lairon, P. Borel, H. Portugal, A. M. Pauli, J. C. Hauton, and H. Lafont. 1987. Effect of pectin, wheat bran and cellulose on serum lipids and lipoproteins in rats fed on a low- or high-fat diet. Br J Nutr 58 (3):405-13.

Vuholm, S., L. M. Arildsen Jakobsen, K. Vejrum Sorensen, U. Kehlet, A. Raben, and M. Kristensen. 2014. Appetite and food intake after consumption of sausages with $10 \%$ fat and added wheat or rye bran. Appetite 73:205-11.

Vuksan, V., A. L. Jenkins, D. J. Jenkins, A. L. Rogovik, J. L. Sievenpiper, and E. Jovanovski. 2008. Using cereal to increase dietary fiber intake to the recommended level and the effect of fiber on bowel function in healthy persons consuming North American diets. Am J Clin Nutr 88 (5):1256-62.

Waliszewski, P., M. Blaszczyk, E. Wolinska-Witort, M. Drews, M. Snochowski, and R. E. Hurst. 1997. Molecular study of sex steroid receptor gene expression in human colon and in colorectal carcinomas. J Surg Oncol 64 (1):3-11.

Walker, A. W., J. Ince, S. H. Duncan, L. M. Webster, G. Holtrop, X. Ze, D. Brown, M. D. Stares, P. Scott, A. Bergerat, P. Louis, F. McIntosh, A. M. Johnstone, G. E. Lobley, J. Parkhill, and H. J. Flint. 2011. Dominant and diet-responsive groups of bacteria within the human colonic microbiota. ISME J 5 (2):220-30. doi: 10.1038/ismej.2010.118.

Walters, R. L., I. M. Baird, P. S. Davies, M. J. Hill, B. S. Drasar, D. A. Southgate, J. Green, and B. Morgan. 1975. Effects of two types of dietary fibre on faecal steroid and lipid excretion. Br Med J 2 (5970):536-8.

Wang, Tao, Xiuhua Sun, Zhanxiang Zhou, and Guibing Chen. 2012. Effects of microfluidization process on physicochemical properties of wheat bran. Food Res Int 48 (2):742-747. doi: https://doi.org/10.1016/j.foodres.2012.06.015. 
Watanabe, K., B. S. Reddy, J. H. Weisburger, and D. Kritchevsky. 1979. Effect of dietary alfalfa, pectin, and wheat bran on azoxymethane-or methylnitrosourea-induced colon carcinogenesis in F344 rats. J Natl Cancer Inst 63 (1):141-5.

Watzke, Heribert J. 1998. Impact of processing on bioavailability examples of minerals in foods. Trends Food Sci Technol 9 (8-9):320-327. doi: http://doi.org/10.1016/S09242244(98)00060-0.

Weaver, C. M., R. P. Heaney, B. R. Martin, and M. L. Fitzsimmons. 1991. Human calcium absorption from whole-wheat products. J Nutr 121 (11):1769-75.

Weaver, C. M., R. P. Heaney, D. Teegarden, and S. M. Hinders. 1996. Wheat bran abolishes the inverse relationship between calcium load size and absorption fraction in women. $J$ Nutr 126 (1):303-7.

Weber, T. E., and B. J. Kerr. 2012. Metabolic effects of dietary sugar beet pulp or wheat bran in growing female pigs. J Anim Sci 90 (2):523-32. doi: 10.2527/jas.2010-3613.

Wilson, R. B., D. P. Hutcheson, and L. Wideman. 1977. Dimethylhydrazine-induced colon tumors in rats fed diets containing beef fat or corn oil with and without wheat bran. Am J Clin Nutr 30 (2):176-81.

Wood, P.J., E. Arrigoni, S.S. Miller, and Renato Amadò. 2002. Fermentability of oat and wheat fractions enriched in (Beta)-glucan using human fecal inoculation. Cereal Chem $79: 445-454$.

Wyman, J. B., K. W. Heaton, A. P. Manning, and A. C. Wicks. 1976. The effect on intestinal transit and the feces of raw and cooked bran in different doses. Am J Clin Nutr 29 (12):1474-9.

Ye, E. Q., S. A. Chacko, E. L. Chou, M. Kugizaki, and S. Liu. 2012. Greater whole-grain intake is associated with lower risk of type 2 diabetes, cardiovascular disease, and weight gain. J Nutr 142 (7):1304-13. doi: 10.3945/jn.111.155325. 
Young, G. P., A. McIntyre, V. Albert, M. Folino, J. G. Muir, and P. R. Gibson. 1996. Wheat bran suppresses potato starch--potentiated colorectal tumorigenesis at the aberrant crypt stage in a rat model. Gastroenterology 110 (2):508-14.

Yu, Liangli, Kequan Zhou, and John W Parry. 2005. Inhibitory effects of wheat bran extracts on human LDL oxidation and free radicals. LWT - Food Sci tech 38 (5):463-470. doi: http://dx.doi.org/10.1016/j.lwt.2004.07.005.

Zhang, D.C., and W.R. Moore. 1997. Effect of Wheat Bran Particle Size on Dough Rheological Properties. J Sci Food Agric 74:490-496.

Zhao, H. M., X. N. Guo, and K. X. Zhu. 2017. Impact of solid state fermentation on nutritional, physical and flavor properties of wheat bran. Food Chem 217:28-36. doi: 10.1016/j.foodchem.2016.08.062.

Zhao, Z., Y. Egashira, and H. Sanada. 2004. Ferulic acid is quickly absorbed from rat stomach as the free form and then conjugated mainly in liver. J Nutr 134 (11):3083-8.

Zhou, K., L. Su, and L. L. Yu. 2004. Phytochemicals and antioxidant properties in wheat bran. J Agric Food Chem 52 (20):6108-14. doi: 10.1021/jf049214g.

Zhu, KeXue, Sheng Huang, Wei Peng, HaiFeng Qian, and HuiMing Zhou. 2010. Effect of ultrafine grinding on hydration and antioxidant properties of wheat bran dietary fiber. Food Res Int 43 (4):943-948. doi: http://dx.doi.org/10.1016/j.foodres.2010.01.005.

Zielinski, Henryk, Halina Kozlowska, and Bogdan Lewczuk. 2001. Bioactive compounds in the cereal grains before and after hydrothermal processing. Innov Food Sci Emerg Technol. 2 (3):159-169. doi: http://doi.org/10.1016/S1466-8564(01)00040-6.

Zoran, D. L., N. D. Turner, S. S. Taddeo, R. S. Chapkin, and J. R. Lupton. 1997. Wheat bran diet reduces tumor incidence in a rat model of colon cancer independent of effects on distal luminal butyrate concentrations. J Nutr 127 (11):2217-25. 


\section{AKNOWLEDGEMENTS}

This research was performed as a part of the SBO BRANDING project, which was funded by ‘Vlaams Agentschap Innoveren en Ondernemen' (Vlaio), Belgium (grant no. 130028). We would also like to thank Boushra Dalile for helping us with making the figures. 


\section{TABLES}

Table 1. Overview of animal and human intervention studies with (modified) wheat bran on the metabolic activity of the microbiota. In animal studies, caecal, portal and faecal concentrations of SCFA were measured whereas human studies were mainly limited to faecal SCFA concentrations.

\begin{tabular}{|c|c|c|c|c|c|c|c|}
\hline Reference & Subjects & Sample size & WB fraction & Comparator & Dosage & Duration & Effects \\
\hline \multicolumn{8}{|l|}{ Animal studies } \\
\hline Fleming et al. 1989 & Pigs & 6 & Coarse WB & Other fibre sources & $11 \%$ diet & 2 weeks & $\uparrow$ caecal $[\mathrm{Bu}]$ \\
\hline Mathers et al. 1994 & Rats & 16 & Coarse WB & Placebo & $20 \%$ diet & 2 weeks & $\begin{array}{l}\downarrow \text { ratio caecal Pro } \\
\uparrow \text { ratio caecal Bu }\end{array}$ \\
\hline McIntyre et al. 1991 & Rats & 6 & Coarse WB & Other fibre sources & $10 \%$ diet & 30 weeks & $\begin{array}{c}\uparrow \text { caecal [Total SCFA] } \\
\uparrow \text { caecal }[\mathrm{Ac}] \\
\uparrow \text { faecal [Total SCFA] } \\
\uparrow \text { faecal }[\text { Pro] }+[\mathrm{Bu}]\end{array}$ \\
\hline \multirow[t]{3}{*}{ Cheng et al. 1987} & Rats & 6 & Coarse WB & Placebo & $220.7 \mathrm{~g} / \mathrm{kg}$ food $^{\mathrm{f}}$ & 10 days & $\begin{array}{c}\uparrow \text { caecal }[\mathrm{Bu}] \\
\uparrow \text { portal }[\text { Total SCFA] } \\
\uparrow \text { portal }[\mathrm{Bu}]\end{array}$ \\
\hline & & 6 & Aleurone WB & & $308.7 \mathrm{~g} / \mathrm{kg}$ food & 10 days & $\begin{array}{r}\uparrow \text { caecal }[\text { Ac }]+[\text { Pro }] \\
\uparrow \text { portal }[\text { Total SCFA }] \\
\uparrow \operatorname{portal}[\text { Ac }]+[\text { Pro }]\end{array}$ \\
\hline & & 6 & Pericarp WB & & $148.7 \mathrm{~g} / \mathrm{kg}$ food & 10 days & $\begin{array}{c}\uparrow \text { caecal }[\mathrm{Bu}] \\
\uparrow \text { portal }[\text { Total SCFA] } \\
\uparrow \operatorname{portal}[\mathrm{Bu}]\end{array}$ \\
\hline McIntosh et al. 2001 & Rats & 20 & Coarse WB & Placebo & $16 \%$ diet & 4 weeks & $\uparrow$ caecal $[\mathrm{Bu}]$ \\
\hline & & 20 & Aleurone WB & & $33 \%$ diet & 4 weeks & $\uparrow$ caecal $[\mathrm{Bu}]$ \\
\hline \multicolumn{8}{|l|}{ Human studies } \\
\hline \multirow[t]{3}{*}{ Ehle et al. 1982} & Healthy subjects & 12 & Coarse WB & Other fibre sources & 12 g/day & 2 weeks & $=$ faecal $[\mathrm{SCFA}]$ \\
\hline & & 12 & WB RPS & & $12 \mathrm{~g} / \mathrm{day}$ & 2 weeks & $=$ faecal $[$ SCFA] \\
\hline & & & WB RPS & & 26 g/day & 9 weeks & $=$ faecal $[$ SCFA] \\
\hline Lewis et al. 1997 & Healthy subjects & 13 & Coarse WB & Laxative products & $28 \mathrm{~g} /$ day & 9 days & $\begin{array}{c}\uparrow \text { faecal [Total SCFA] } \\
\uparrow \text { faecal }[\mathrm{Ac}]+[\mathrm{Bu}]\end{array}$ \\
\hline Salonen et al. 2014 & $\begin{array}{c}\text { Metabolic } \\
\text { syndrome patients }\end{array}$ & 14 & Coarse WB & Resistant starch & $27.7 \mathrm{~g} /$ day & 3 weeks & $=[\mathrm{SCFA}]$ \\
\hline Hallfrisch et al. 1999 & Healthy subjects & 26 & WB RPS & Coarse WB & $12.6 \mathrm{~g} / 100 \mathrm{~g}$ bread & Single administration & $\begin{array}{c}=\text { breath } \mathrm{CH}_{4} \text { and } \mathrm{H}_{2} \\
\text { excretion }\end{array}$ \\
\hline Jenkins et al. 1999 & Healthy subjects & 23 & WB RPS & Coarse WB & $20 \mathrm{~g} / \mathrm{dag}$ & 4 weeks & $\begin{array}{l}\uparrow \text { faecal }[\mathrm{Bu}] \\
\uparrow \text { breath } \mathrm{CH}_{4} \\
\quad \text { excretion } \\
\end{array}$ \\
\hline
\end{tabular}

WB: wheat bran, Bu: butyrate, Pro: propionate, SCFA: short-chain fatty acids, Ac: Acetate, WB RPS: wheat bran with reduced particle size 
Table 2. Phytate content in wheat bran decreases during modification and might result in better mineral availability, which is reduced after consumption of wheat bran. Overview of in vitro studies showing phytate reduction in modified wheat bran, and of animal and human intervention studies with (modified) wheat bran on mineral availability

\begin{tabular}{|c|c|c|c|c|c|c|c|}
\hline Reference & $\begin{array}{l}\text { In vitro/ } \\
\text { Subjects }\end{array}$ & Sample size & WB fraction & Comparator & Dosage & Duration & Effects \\
\hline \multicolumn{8}{|l|}{ In vitro studies } \\
\hline Mosharraf et al. 2009 & In vitro & - & HT-WB & - & - & - & $55 \%$ phytate reduction \\
\hline Zielinski et al. 2001 & In vitro & - & HT-WB & - & - & - & $8 \%$ phytate reduction \\
\hline Manini et al. 2014 & In vitro & - & Fermented WB & - & - & - & $90 \%$ phytate reduction \\
\hline Zhao et al. 2017 & In vitro & - & Fermented WB & - & - & - & $20 \%$ phytate reduction \\
\hline Sanz Penella et al. 2008 & In vitro & - & WB RPS & - & - & - & $\downarrow$ phytate content \\
\hline \multicolumn{8}{|l|}{ Animal studies } \\
\hline Fly et al. 1996 & Chicken & 16 & Coarse WB & No treatment & $5-10 \%$ diet & 2 weeks & $=\mathrm{Fe}$ absorption \\
\hline \multicolumn{8}{|l|}{ Human studies } \\
\hline Cook et al. 1983 & Healthy subjects & 21 & Coarse WB & Placebo & 12 g/day & 2 weeks & $\downarrow \mathrm{Fe}$ absorption \\
\hline Dobbs et al. 1977 & Healthy subjects & 13 & Whole meal bread & White bread & $100 \mathrm{~g}$ bread & Single administration & $\downarrow$ Fe absorption \\
\hline Simpson et al. 1981 & Healthy subjects & 10 & Coarse WB & No treatment & $12 \mathrm{~g}$ & Single administration & $\downarrow$ Fe absorption \\
\hline Weaver et al. 1991 & Healthy subjects & 18 & Coarse WB & $\begin{array}{c}\text { Milk } \\
\text { Coarse WB + Milk }\end{array}$ & $45 \mathrm{~g}$ & Single administration & $\downarrow$ Ca absorption \\
\hline Weaver et al. 1996 & Healthy subjects & 26 & Coarse WB & No treatment & $16 \mathrm{~g}$ & Single administration & $\downarrow$ Ca absorption \\
\hline Sandberg et al. 1982 & Ileostomy patients & 8 & Coarse WB & Low-fibre diet & $16 \mathrm{~g} /$ day & 1 week & $\begin{array}{c}\uparrow:[\mathrm{Zn}] \\
\downarrow:[\mathrm{Fe}] \\
=:[\mathrm{Ca}],[\mathrm{Mg}]\end{array}$ \\
\hline
\end{tabular}

WB: wheat bran, HT-WB: heat treated wheat bran, WB RPS: wheat bran with reduced particle size, Fe: iron, Ca: calcium, Zn: zinc, Mg: magnesium 
Table 3. Overview of human intervention studies with (modified) wheat bran on gastrointestinal transit and stool parameters

\begin{tabular}{|c|c|c|c|c|c|c|c|}
\hline Reference & Subjects & Sample size & WB fraction & Comparator & Dosage & Duration & Effects \\
\hline \multicolumn{8}{|l|}{ Human studies } \\
\hline de Vries et al. 2015 & Healthy subjects & - & Wheat fibre & - & - & - & $\begin{array}{c}\uparrow \text { stool weight } \\
\uparrow \text { dry weight } \\
\uparrow \text { stool frequency } \\
\downarrow \text { transit time }\end{array}$ \\
\hline Kirwan et al. 1974 & $\begin{array}{l}\text { Diverticular disease } \\
\text { patients }\end{array}$ & 5 & WB RPS & Coarse WB & $20 \mathrm{~g} /$ day & 4 weeks & $\uparrow$ transit time \\
\hline Brodribb et al. 1978 & Healthy subjects & 21 & WB RPS & Coarse WB & $20 \mathrm{~g} /$ day & 2 weeks & $\downarrow$ stool weight \\
\hline Heller et al. 1980 & Healthy subjects & 24 & WB RPS & Coarse WB & 32 g/day & 2 weeks & $\begin{array}{l}\uparrow \text { transit time } \\
\downarrow \text { stool weight }\end{array}$ \\
\hline Smith et al. 1981 & $\begin{array}{l}\text { Diverticular disease } \\
\text { patients }\end{array}$ & 6 & WB RPS & Coarse WB & $20 \mathrm{~g} /$ day & 4 weeks & $\begin{array}{l}=\text { transit time } \\
=\text { stool weight }\end{array}$ \\
\hline Walters et al. 1975 & Healthy subjects & 5 & HT-WB & Other fibre source & $39 \mathrm{~g} /$ day & 1 weeks & $\begin{array}{l}79 \% \uparrow \text { wet weight } \\
44 \% \uparrow \text { dry weight }\end{array}$ \\
\hline Wyman et al. 1976 & Healthy subjects & 10 & HT-WB & Coarse WB & $22 \mathrm{~g} /$ day & 2 weeks & $\begin{array}{l}=\text { transit time } \\
=\text { wet weight } \\
=\text { dry weight } \\
=\text { stool frequency }\end{array}$ \\
\hline
\end{tabular}

WB: wheat bran, WB RPS: wheat bran with reduced particle size, HT-WB: heat treated wheat bran 
Table 4. Overview of animal and human intervention studies with (modified) wheat bran on parameters of colorectal cancer.

\begin{tabular}{|c|c|c|c|c|c|c|c|}
\hline Reference & Subjects & Sample size & WB fraction & Comparator & Dosage & Duration & Effects \\
\hline \multicolumn{8}{|l|}{ Animal studies } \\
\hline Alabaster et al. 1996 & Rats & 5 & Coarse WB & $\begin{array}{c}\text { Phytic acid; } \\
\text { Vitamin E; } \\
\text { Physillium; Folic } \\
\text { acid; } \beta \text {-carotene }\end{array}$ & $8 \%$ diet & 12 weeks & $\begin{array}{c}\downarrow \text { total tumours } \\
=\text { adenomas } \\
=\text { adenocarcinomas }\end{array}$ \\
\hline Barnes et al. 1983 & Rats & 15 & Coarse WB & Other fibre sources & $20 \%$ diet & 4 weeks & $\begin{array}{c}\uparrow \text { survival } \\
\downarrow \text { large bowel tumours }\end{array}$ \\
\hline Reddy et al. 1981 & Rats & 12 & Coarse WB & Other fibre sources & $15 \%$ diet & 20 weeks & $\begin{array}{c}\downarrow \text { small intestinal tumours } \\
\downarrow \text { large bowel tumours } \\
\downarrow \text { colon adenomas } \\
\downarrow \text { colon adenocarcinomas }\end{array}$ \\
\hline Watanabe et al. 1979 & Rats & 30 & Coarse WB & Other fibre sources & $15 \%$ diet & 20 weeks & $\downarrow$ large bowel tumours \\
\hline Wilson et al. 1977 & Rats & 44 & Coarse WB & Low-fibre diet & $20 \%$ diet & 30 weeks & $\begin{array}{c}\downarrow \text { large bowel tumours } \\
\downarrow \text { malignant tumours } \\
\downarrow \text { colon polyps }\end{array}$ \\
\hline Bauer et al. 1979 & Rats & 40 & Coarse WB & Other fibre sources & $20 \%$ diet & 15 weeks & $=$ number colorectal tumours \\
\hline Jacobs 1983 & Rats & 48 & Coarse WB & Low-fibre diet & $20 \%$ diet & 31 weeks & $\begin{array}{c}\uparrow \text { tumor yield } \\
\uparrow \text { benign tumors } \\
\uparrow \text { malignant tumors }\end{array}$ \\
\hline McIntyre et al. 1993 & Rats & 15 & Coarse WB & Other firbe sources & $10 \%$ diet & 33 weeks & $\downarrow$ malignant tumours \\
\hline McIntosh et al. 2001 & Rats & & $\begin{array}{c}\text { Coarse WB } \\
\text { Aleurone WB }\end{array}$ & Placebo & $\begin{array}{l}16 \% \text { diet } \\
33 \% \text { diet }\end{array}$ & & $\begin{array}{l}\downarrow \text { intestinal tumours } \\
\downarrow \text { intestinal tumours }\end{array}$ \\
\hline \multicolumn{8}{|l|}{ Human studies } \\
\hline Alberts et al. 1990 & Patients with CRC history & 17 & Coarse WB & Low-fibre diet & $13.5 \mathrm{~g} /$ day & 2 months & $\downarrow$ cell proliferation \\
\hline Alberts et al. 1997 & Patients with CRC history & 100 & Coarse WB & Low-fibre diet & $13.5 \mathrm{~g} / \mathrm{day}$ & 9 months & $=$ cell proliferation \\
\hline DeCosse et al. 1989 & Patients with familial polyposis & 29 & Coarse WB & $\begin{array}{l}\text { Vitamin } \mathrm{C} \text { and } \mathrm{E} \\
\text { supplementation }\end{array}$ & $22.5 \mathrm{~g} /$ day & 4 years & $\begin{array}{c}=\text { number malignant polyps } \\
=\text { number benign polyps } \\
\downarrow \text { size of benign polyps }\end{array}$ \\
\hline MacLennan et al. 1995 & Patients with CRC history & 306 & Coarse WB & $\beta$-carotene & 25 g/day & 4 years & No prevention for new adenomas \\
\hline
\end{tabular}

WB: wheat bran, CRC:colorectal cancer 


\section{FIGURES}

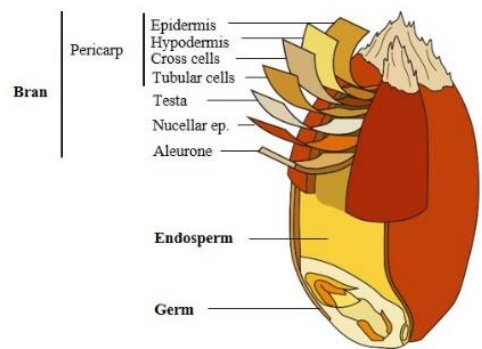

(a)

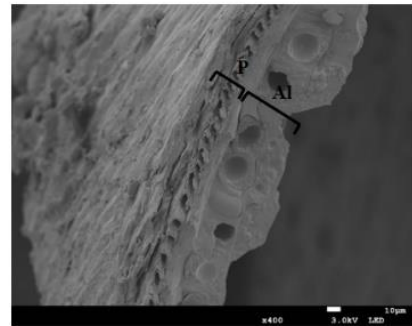

(b)

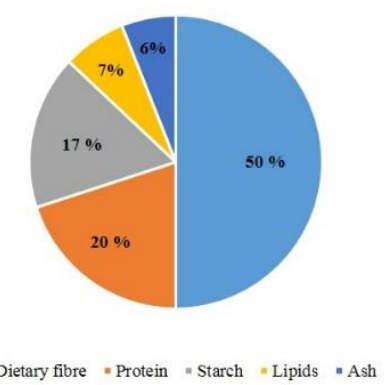

(c)

Figure 1. (a) Composition of the wheat kernel. (b) Scanning Electron Microscopy image of a cross section of wheat bran. Al: Aleurone; P: Pericarp. (c) Average wheat bran composition based on dry matter basis. 


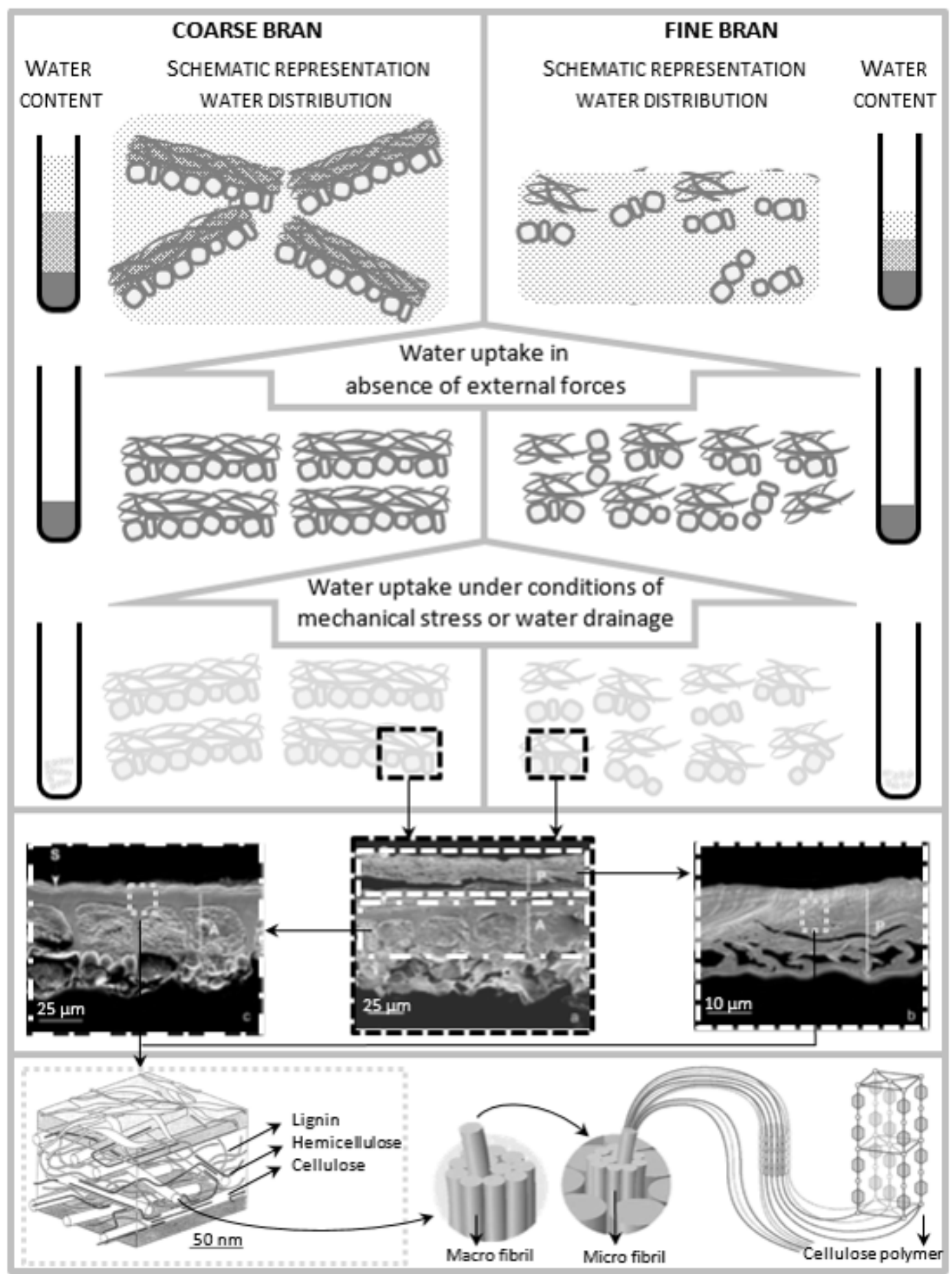

Figure 2. Wheat bran with reduced particle size has a lower water holding capacity compared to coarse bran, due to the loss of micropores and reduced void space between particles. Reprinted from Jacobs et al., Food Chem., 2015, 179:296-304. Copyright 2015 by Elsevier Ltd. Reprinted with permission. 


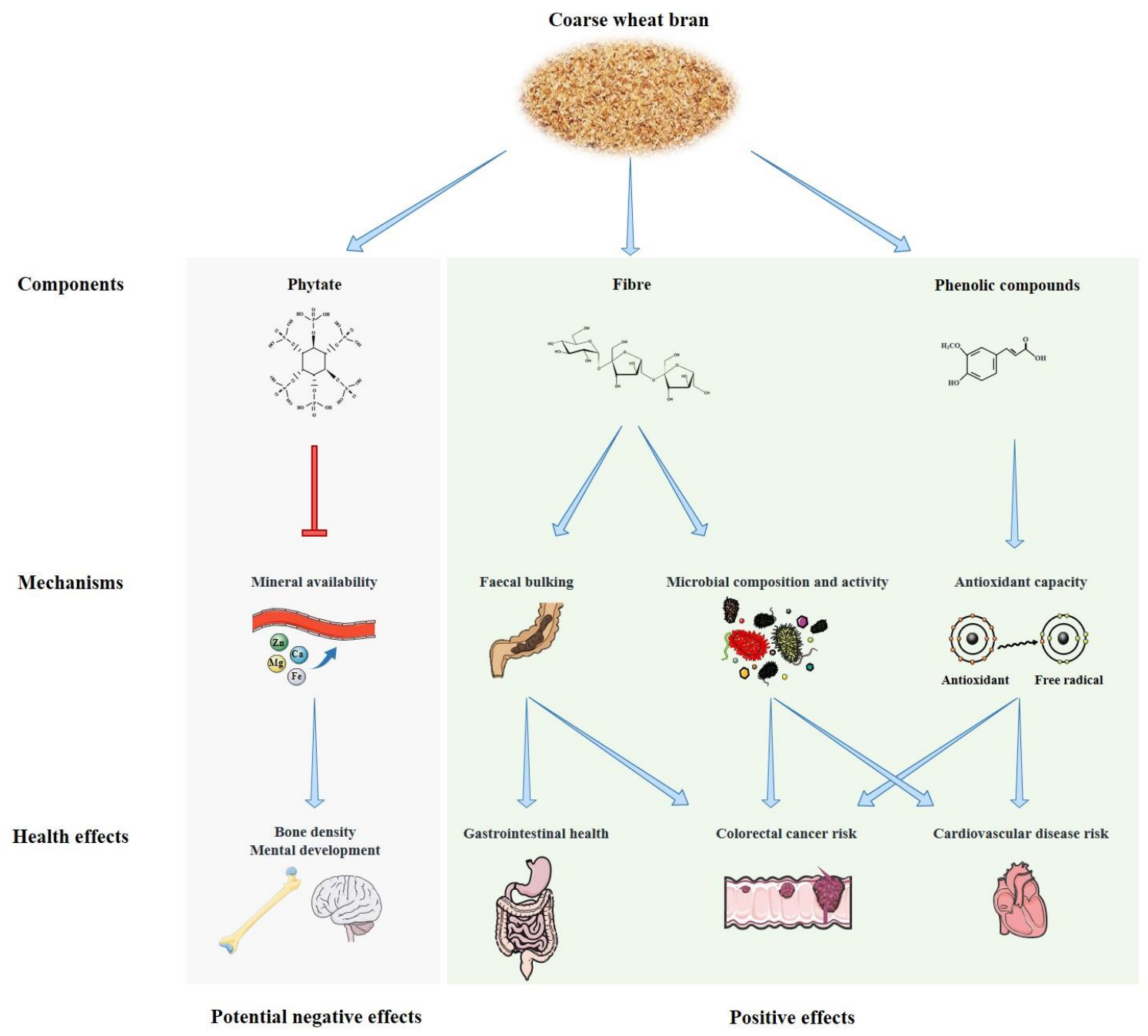

Figure 3. Coarse wheat bran is associated with several health effects that are possibly mediated by different mechanisms. Modifying wheat bran may change those mechanisms, thereby affecting the health effects obtained by coarse wheat bran. 


\section{FIGURE CAPTIONS}

Figure 2. (a) Composition of the wheat kernel. (b) Scanning Electron Microscopy image of a cross section of wheat bran. Al: Aleurone; P: Pericarp. (c) Average wheat bran composition based on dry matter basis.

Figure 2. Wheat bran with reduced particle size has a lower water holding capacity compared to coarse bran, due to the loss of micropores and reduced void space between particles. Reprinted from Jacobs et al., Food Chem., 2015, 179:296-304. Copyright 2015 by Elsevier Ltd. Reprinted with permission.

Figure 3. Coarse wheat bran is associated with several health effects that are possibly mediated by different mechanisms. Modifying wheat bran might impact those mechanisms, thereby affecting the health effects obtained by coarse wheat bran. 